\title{
Impact of improved client-provider interaction on women's achievement of fertility goals in Egypt
}

\author{
Laila Nawar \\ Ibrahim Kharboush \\ Magdi A. Ibrahim \\ Hesham Makhlouf \\ Susan E. Adamchak
}

Follow this and additional works at: https://knowledgecommons.popcouncil.org/departments_sbsr-rh

Part of the Demography, Population, and Ecology Commons, Health Services Research Commons, and the International Public Health Commons

How does access to this work benefit you? Let us know!

\section{Recommended Citation}

Nawar, Laila, Ibrahim Kharboush, Magdi A. Ibrahim, Hesham Makhlouf, and Susan E. Adamchak. 2004. "Impact of improved client-provider interaction on women's achievement of fertility goals in Egypt," FRONTIERS Final Report. Washington, DC: Population Council. 


\title{
Impact of Improved Client-Provider Interaction on Women's Achievement of Fertility Goals in Egypt
}

\author{
December 2004
}

\author{
Laila Nawar and \\ Ibrahim Kharboush \\ Frontiers in Reproductive Health Program \\ Magdi A. Ibrahim, and \\ Hesham Makhlouf \\ Cairo Demographic Center (CDC) \\ Susan Adamchak \\ Frontiers in Reproductive Health Program \\ Family Health International
}

This study was funded by the U.S. AGENCY FOR INTERNATIONAL DEVELOPMENT (USAID) under the terms of Cooperative Agreement Number HRN-A-00-98-00012-00, Population Council In-house project 5800-13038, and Subagreement number AI02.02A. The opinions expressed herein are those of the authors and do not necessarily reflect the views of USAID. 


\section{EXECUTIVE SUMMARY}

Contraceptive prevalence is relatively high in Egypt with 56 percent of currently married women use a method according to the Egypt 2000 Demographic and Health Survey (El Zanaty and Way 2001). However, the family planning program is concerned about discontinuation rates showing that three in every 10 users stop using a method within the first 12 months of adoption. Evidence also suggests that the quality of care in Ministry of Health and Population (MOHP) clinics has improved and in many respects is quite good, yet some elements remain inadequate.

A two-phase operations research study was launched in Egypt in early 2000 with the goal of demonstrating how improving the quality of client-provider interaction (CPI) could be achieved in large health care systems, specifically in relation to family planning. The study was designed to explore how CPI improvements could enhance family planning knowledge, method continuation rates, client satisfaction, and achievement of fertility goals. This study forms part of a global initiative conducted in comparable fashion in two other countries, Peru (León et al. 2003) and Uganda (Okullo et al. 2003).

\section{Research Questions}

The CPI study in Egypt has been designed to answer the following research questions:

1. Can measurable improvements be made in client-provider interaction by introducing practical systems-oriented, provider-oriented, and client-oriented interventions?

2. If client-provider interactions are improved, will there be measurable improvements in: (a) women's knowledge about available contraceptive choices; (b) women's satisfaction with contraception; (c) continued use of any method; (d) women's ability to obtain their preferred method (unless there is clear contraindication); (e) correct use of the chosen method; (f) prompt switching to another method; (g) women's ability to achieve their fertility goals or reproductive intentions (to delay a first birth, to space or to limit pregnancies); (h) increased numbers of new and continuing clients attending the clinic; and (i) a more diverse method mix in family planning clinics?

3. What is the impact of the intervention package on the job satisfaction of providers?

4. What are the costs of the various components of the intervention (training, technical assistance, additional monitoring, and client visits)?

5. Do the costs of carrying out family planning visits increase, and if so, by how much?

Research questions (1), (3), (4) and (5) were investigated in Phase I of the study (SPAAC 2002). Research question (2) was examined through Phase II of the study (the present study) in which a cohort of new family planning acceptors was enrolled and followed-up for a period of 13 months after the index visit. Client outcomes were measured at seven and 13 months through home interviews. 
The study takes the form of a panel study in which clients who qualify for inclusion and who visited the study sites during the data collection period (the index visit) were followed-up through home interviews at seven and 13 months following the index visit. This provided data on the family planning continuation rate at six and 12 months, following the improved CPI intervention.

The study sample included 300 women in each of the study groups, intervention and control, for the seven month home follow-up interviews, and 295 in each study group for the 13 month home follow-up interviews. The seven month follow-up interviews took place during March 2002, and the 13 month follow-up interviews took place during September 2002.

Study findings showed that women in both study groups were very close with regard to current age (mean $=29.5$ years) and their husbands' age (mean $=36$ years). Women in the intervention group were slightly less educated. Also, significantly more women in the intervention group lived in rural areas compared with women in the control group.

Indicators of achieved and desired fertility were significantly higher among women in the intervention group than the control group. The mean number of living children was 2.9 for the intervention group compared with 2.7 for the control group. Also, more women in the intervention group wanted to have additional children compared with the control group.

Data on the family planning method received at the index visit indicate non-significant differences. About the same proportion of women in both study groups received an IUD (about $61 \%$ ). However, fewer women in the intervention group received injectables compared with women in the control group ( $24 \%$ versus $32 \%$, respectively), while more women in the intervention group received combined oral contraceptive (COC) or pill (14\% versus $6 \%)$.

Only slightly more than one-half of women in the intervention and control clinics made return visits to the clinic within seven months of the index visit. Slightly less than one-half of women made return visits to the study clinics between seven and 13 months of the index visits. The majority of women who did not make any return visits to the study clinics reported that they were comfortable with using their long-acting method, thus saw no reason to visit the clinic. Almost all of the women who stopped visiting the clinics reported that none of the clinic staff visited them at home to investigate reasons for dropping out.

The improvement in providers' technical knowledge, information that should be exchanged with clients, as well as aspects of client-provider interaction that was documented in Phase I of the study did not result in improvement in client's knowledge about available family planning methods or method currently used. Thus, little or no differences were indicated between the two study groups in this regard.

However, for women currently using the IUD, the findings indicate improvement in the mean percent general knowledge score about the IUD for women in the intervention group (about 26\% and $30 \%$ in the seven and 13 month interviews, as compared with the control group with $23 \%$ and $26 \%$, respectively, $\mathrm{p}<0.01$ ). 
The study findings indicate improvement in mean percent general knowledge score of the IUD and pill in the intervention group compared with the control group, among women who received those methods at the index visit and continued using them without interruption.

Although lactational amenorrhea (LAM) is an important form of natural family planning that is widely practiced among Egyptian woman, especially in rural areas, the study findings indicate that most women do not know how to use it effectively. Women in both study groups know about only one criterion for LAM to be an effective form of birth control (absence of menses). Very few women reported knowledge of the other two criteria (i.e., breastfeeding up to 6 months after delivery, and exclusive breastfeeding).

Knowledge of warning signs of family planning methods was higher in the intervention group compared with the control group, with few exceptions. The mean percent knowledge score of warning signs for women currently using the pill in the intervention group was 44.1 compared to 34.5 for the control group for the seven month follow-up visit $(\mathrm{p}<0.01)$. The mean scores of warning signs for the IUD and injectables were also higher for the intervention group, but differences were not significant. Also, knowledge of correct use of the IUD was higher among women in the intervention group compared to the control at both the seven and 13 month followup interviews.

Once they received a method at the index visit, about one-quarter of women in each study group switched to another method during the period between the index visit (July/August 2001) and the 13 month follow-up interview (September 2002). Switching to the second method occurred after a fairly short period of method discontinuation (mean period $=1.03$ months for the intervention and 0.90 for the control, $\mathrm{p}<0.01$ ).

The study findings reflected a rather low level of knowledge about method side effects among the two study groups. Knowledge of the side effects of the pill was less than 30 percent for both study groups, while knowledge of the side effects of the IUD was about 37 percent for both study groups. In general, women in the intervention group were more likely to know about method side effects, more likely to experience them, and more likely to be able to tolerate these side effects compared with women in the control group.

Client satisfaction with services provided at the study clinics was found to be the outcome indicator that showed the most difference between study groups. About 76 percent of women in the intervention group were satisfied with the physical aspects of clinic preparedness at the seven month follow-up visit as compared with 31 percent of women in the control group. Comparable figures for the 13 month follow-up interview were 88 percent versus 32 percent $(\mathrm{p}<0.01)$. Likewise, satisfaction with clinic services received at the index visit (providers' counseling skills and technical competence) was significantly higher among women in the intervention group as compared with women in the control group at both follow-up visits ( $72 \%$ versus $55 \%$, and $81 \%$ versus $61 \%$ at the seven and 13 months follow-up visits respectively, $\mathrm{p}<0.01$ ).

The data also indicated that between one-third and two-fifths of women in the two study groups changed their reproductive intentions since the index visit at which they reported wanting no 
more children. More women in the control group changed their reproductive intentions and wanted to become pregnant.

On the other hand, a few women were not able to achieve their reproductive intentions. They were exposed to unplanned pregnancy due to various reasons (e.g., incorrect method use, method side effects, and health concerns), reflecting poor quality of care and counseling. About twofifths of women in both study groups who discontinued method use fell into this category.

The study findings indicated some gaps in service provision. The qualitative study indicates that in some situations physicians were not available to react to women's queries; they were busy with other activities (such as vaccinations), or they provided incorrect advice.

Finally, the study findings did not depict significant differences in method continuation rates between the two study groups. Both study groups experienced nearly similar continuation rates for the IUD (life table cumulative rates were $80 \%$ for both groups after 12 months of use). Multiple regression analysis showed that women who were satisfied with the method and had more knowledge about its correct use were more likely to continue method use. Also, women who continued visiting the index clinic continued method use longer than women who dropped out.

Based on the study findings, the recommendations are the following:

1. Continue to develop innovative information, education and communication (IEC) messages that influence women's fertility preferences.

2. Develop further IEC components that promote women's knowledge about criteria for LAM as an effective family planning method.

3. Provide continuous training to clinic health providers to demonstrate sensitivity and understanding of women's needs in their localities.

4. Continue to emphasize the importance of encouraging women to make regular clinic follow-up visits as well to seek medical advice when faced with problems with method use.

5. Consider reasonable mechanisms to train and educate private physicians and service providers of other programs. This would help women receive the same basic information even when shifting from one health facility to another. 


\section{TABLE OF CONTENTS}

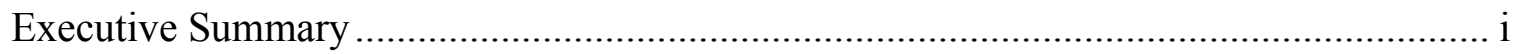

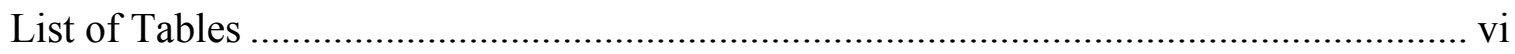

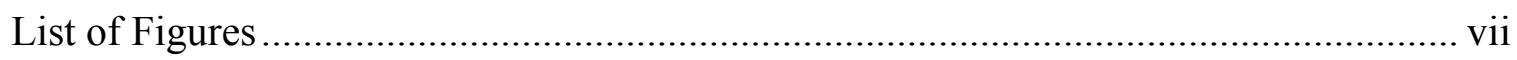

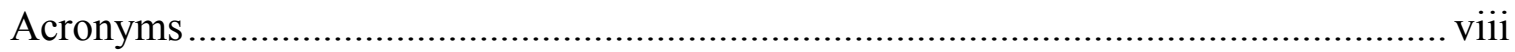

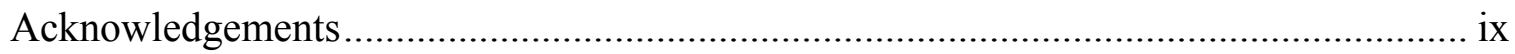

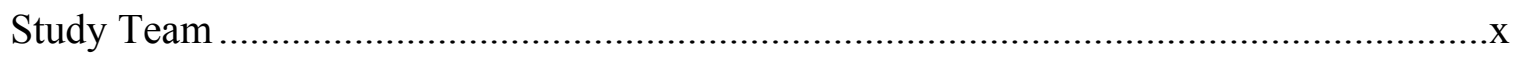

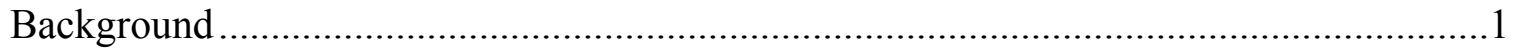

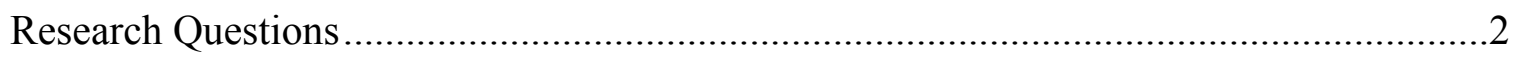

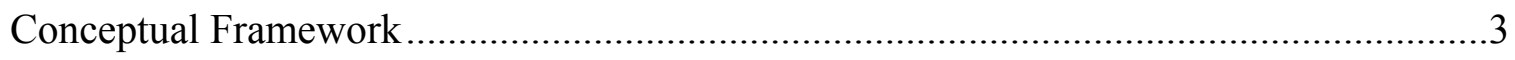

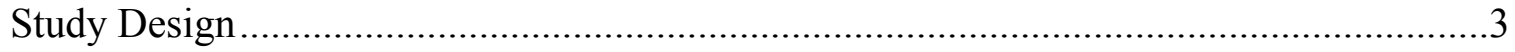

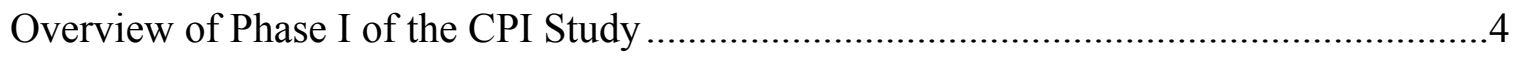

The Present Study: Phase II of the CPI Study ...............................................................

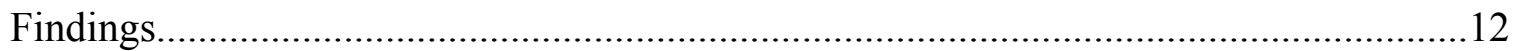

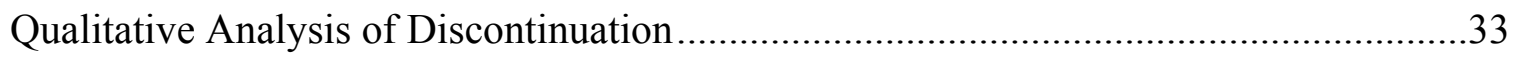

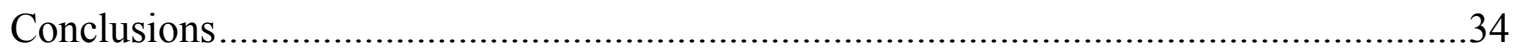

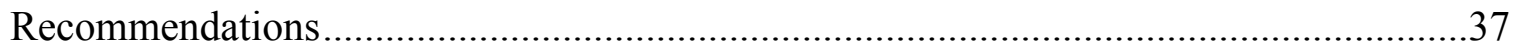

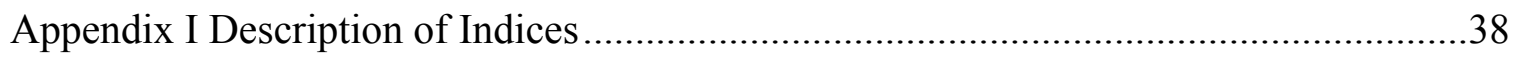

Appendix II Case Studies from the Qualitative Research Findings ...................................41

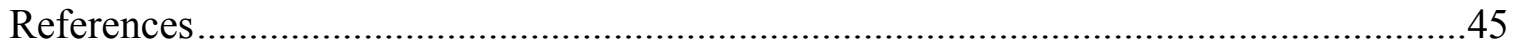




\section{LIST OF TABLES}

Table 1: Sample size, seven month and 13 month follow-up home visits................................

Table 2: Selected demographic and socio-economic characteristics for women in the intervention and control groups, at seven month follow-up visit

Table 3: Selected reproductive health characteristics for women in the intervention and control groups at seven month follow-up visit

Table 4: Family planning methods use at seven and 13 month follow-up visits

Table 5: Percent of clients visiting index clinics for family planning services at seven and 13 months

Table 6: Percent distribution of clients who reported visiting the index clinic, by number of visits

Table 7: Reasons cited for stopping clinic visits

Table 8: Percent of women reporting a visit by clinic staff after dropping out of the clinic...17

Table 9: General knowledge of family planning methods among women at seven month and 13 month follow-up interviews

Table 10: Knowledge score of criteria for LAM to be effective as a family planning method 18

Table 11: Mean percent general knowledge score of method currently used for women at seven month and 13 month follow-up interviews.....

Table 12: Mean percent general knowledge score by method among women who received the specified methods at the index visit, and continued using same method at seven month and 13 month interviews.

Table 13: Mean percent knowledge score of warning signs for women currently using the specified methods at seven month and 13 month follow-up interviews

Table 14: Mean percent score of knowledge of correct use for women currently using the specified methods at seven month and 13 month follow-up interviews

Table 15: Percentage distribution of switchers between the index visit in and the 13 month follow-up interview by method-free interval and mean period of non-use .....

Table 16: Distribution of clients at the 13 month follow-up interview who ever switched to another method since index visit, by type of method received at the index visit and method currently used.....

Table 17: Percent of women reporting satisfaction with method received at index visit: satisfaction score

Table 18: Percent of women reporting method side effects at seven month and 13 month follow-up interviews 
Table 19: Percent of women reporting satisfaction with clinic's physical preparedness for providing family planning services: satisfaction score

Table 20: Percent of women reporting satisfaction with services provided in the clinic at the index visit.

Table 21: Percent of women reporting satisfaction with services provided in the clinic at the index visit: satisfaction score

Table 22: Contraceptive use dynamics at seven and 13 month home interviews.

Table 23: Cumulative continuation rates for all methods for the intervention and control groups

Table 24: Cumulative continuation rates for the IUD for the intervention and control groups

Table 25: Cumulative continuation rates for the pill for intervention and control groups .......30

Table 26: Summary of the results of the stepwise logistic regression analysis of the factors related to use of contraception at the seven month follow-up visit

Table 27: Summary of the results of the stepwise logistic results analysis of the factors related to use of contraception at the 13 month follow-up interview

\section{LIST OF FIGURES}

Figure 1: Impact of improved client-provider interaction on women's achievement of fertility goals - Conceptual Framework

Figure 2: Cumulative continuation rates for intervention and control groups (all methods) ..28

Figure 3: Cumulative continuation rates for intervention and control groups (IUD)

Figure 4: Cumulative continuation rates for intervention and control groups (pill)..... .30 


\section{ACRONYMS}

CDC Cairo Demographic Center

COC Combined Oral Contraceptive

CPI Client-Provider Interaction

EDHS Egypt Demographic Health Survey

FHI Family Health International

IEC Information, Education, and Communication

IUD Intrauterine Device

LAM Lactational Amenorrhea Method

MOHP Ministry of Health and Population

SPAAC Social Planning Analysis and Administration Consultants 


\section{ACKNOWLEDGEMENTS}

I would like to thank all the teams who made this work possible. Because of the effective coordination and cooperation among the Ministry of Health and Population, Cairo Demographic Center and the Population Council, the study on "The Impact of Improved Client-Provider Interaction on Women's Achievement of Fertility Goals" has been impressive and raised a number of important recommendations for program and policy directions.

My deep thanks go to the USAID for providing financial support for this study and to the Population Council for the effective monitoring of the study activities throughout all study phases as well as the valuable technical assistance received.

Special thanks are also due to the Population and Family Planning Sector of the Ministry of Health and Population (MOHP) for facilitating the implementation of field activities of this study phase. Many thanks are also due to all local MOHP directors and supervisors in the study governorates for providing all support and logistics needed.

The project coordinator, Dr. Magdi A. Ibrahim, all members of the project team as well as other CDC staff deserve special acknowledgment for their hard work during all phases of the project implementation.

Finally, I would like to thank the Central Agency for Public Mobilization and Statistics (CAPMAS) for the continuous support and cooperation in providing necessary approvals for data collection.

Prof. Hesham Makhlouf

CDC Director 


\section{STUDY TEAM}

\section{Steering Committee}

Prof. Hesham Makhlouf

Dr. Yehia El Hadidi

Dr. Magdi A. Ibrahim

Other CDC Technical Team

Mr. Saad Zaghloul Amin

Dr. Seham Mohamed El-Sherif

Mrs. Fatten Abdel Fattah

Mrs. Nadia Fahmy

Mr. Amr El Said

Ms. Manal El-Feky

\section{Data Collection Team}

Dr. Gihan A.Shawki

Dr. Mohamed Moustafa

Dr. Ahmed El Zanney

Mr. Sobhi Ismail

Mr. Shawki Yassin

Mr. Mohamed El Husseiny

Mrs. Hana'a El-Husseiny

Mrs. Ghada Moustafa

Mrs. Amal Fouad

Mrs. Safa'a Ali

Mrs. Aida Sayed

Mrs. Afaf Abbas

Mrs. Yosr Abdel Fattah

Mrs. Gala'a Helmi

Ms. Mona Ismail

Mrs. Maha El-Sayed

Mrs. Nadia Gamil

Mrs. Salwa Ibrahim

Mrs. Amal Mohamed

Mrs. Samia Mohamed

Mrs. Fatten Farag

\section{Data Processing Team}

Mrs. Mona Tawfik Youssef

Mr. Khaled El-Ghereni

Mr. Ahmed Salah

Mr. Mostafa Refa'at

Mr. Ahmed Essam Eddin
Principal Investigator

Undersecretary of Population and Family Planning Sector MOHP

Project Coordinator

Senior Statistician

Technical Assistant

Technical Assistant

Technical Assistant

Technical Assistant

Technical Assistant

Field Work Coordinator

Field Work Supervisor

Field Work Supervisor

Field Work Supervisor

Field Work Supervisor

Field Work Supervisor

Interviewer

Interviewer

Interviewer

Interviewer

Interviewer

Interviewer

Interviewer

Interviewer

Interviewer

Interviewer

Interviewer

Interviewer

Interviewer

Interviewer

Interviewer

Head of data processing team

Data Processor

Data Processor

Data Processor

Data Processor 


\section{Administrative Support}

Mr. Salah Kamel

Mrs. Iman Nasri

Mr. Hesham El-Kashef

\section{Local MOHP Directors and Supervisors}

\section{Sharkia Governorate}

Dr. Mohamed Khairy

Undersecretary of Health and Population

Dr. Abdel Hamid El Borai'e

Governorate Family Planning Manager

Dr. Hamida El Hoseiny

Mrs. Mahasen Khatab

Governorate Medical Supervisor

Dr. Iman Hussein

Governorate Nursing Supervisor

Dr. Somaya Said

Ms. Safia Mahmoud

Dr. Zeinab Abdel Aziz

Dr. Essam Osman

Family Planning Manager, Zagazig District

Medical Supervisor, Zagazig District

Nursing Supervisor, Zagazig District

Family Planning Manager, Hehya District

Medical Supervisor, Hehya District

Ms. Ahlam Refa'at

Nursing Supervisor, Hehya District

\section{Menoufia Governorate}

Dr. Mohamed El Gendy

Dr. Afaf Soliman

Dr. Mohamed Sharshar

Ms. Hoda Ali

Dr. Samira Abdel Ghany

Ms. Nagat Khair

Dr. Mohamed El Mohamady

Dr. Aziza Ismail

Ms. Ta'adel Abdel Maksoud

Kafr El Sheikh Governorate

Dr. Magdi Hassan

Dr. Salwa Ammar

Undersecretary of Health and Population

Governorate Family Planning Manager

\section{Behera Governorate}

Dr. Samy Mosleh

Undersecretary of Health and Population

Governorate Family Planning Manager

Governorate Medical Supervisor

Governorate Nursing Supervisor

Family Planning Manager, Quesna District

Nursing Supervisor, Quesna District

Family Planning Manager, Ahmoun District

Medical Supervisor, Ashmoun District

Nursing Supervisor, Ashmoun District

Dr. Nagwa Soltan

Undersecretary of Health and Population

Governorate Family Planning Manager

\section{FRONTIERS Staff}

$\begin{array}{lll}\text { Study Monitors } & \text { Dr. Laila Nawar } & \text { WANA Regional Advisor } \\ & \text { Dr. Ibrahim Kharboush } & \text { Country Fellow } \\ & \text { Dr. Barbara Janowitz } & \text { Director, Health Services Research } \\ & \text { Dr. Susan Adamchak } & \text { Global Agenda Coordinator } \\ \text { Admin. Support } & \text { Ms. Gihan Hosny } & \text { Administrative Assistant } \\ & \text { Ms. Magda Fayek } & \text { Program Associate }\end{array}$

${ }^{*}$ Until December 2003 


\section{BACKGROUND}

Contraceptive prevalence is relatively high in Egypt with 56 percent of currently married women use a method according to the Egypt 2000 Demographic and Health Survey (El Zanaty and Way 2001). However, the family planning program is concerned about discontinuation rates showing 3 in every 10 users stop using a method within the first 12 months of adoption. The qualityrelated discontinuation rate is estimated at 22 percent.

Evidence suggests that the quality of care in Ministry of Health and Population (MOHP) clinics has improved and in many respects is quite good, yet some elements remain inadequate. Providing counseling is a problem in most settings (El Zanaty and Associates 1998). Inadequate client-provider interaction (CPI) may be responsible for high rates of

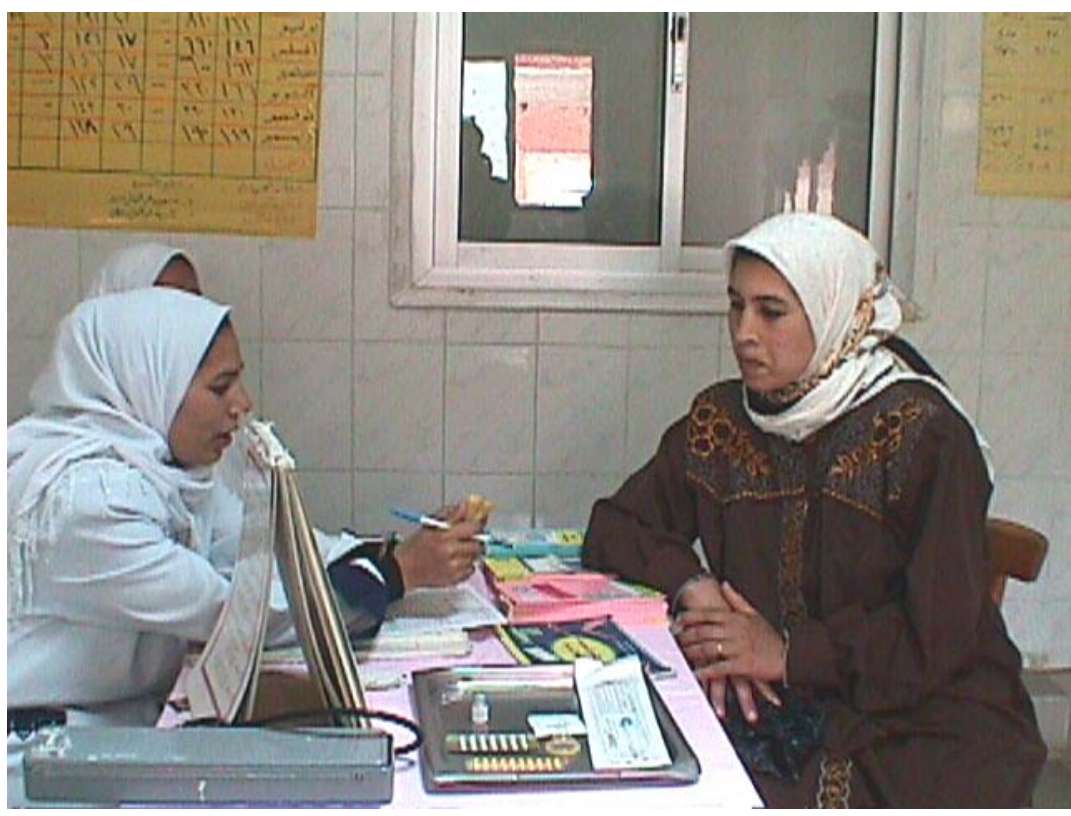
method discontinuation in part because it can result in incorrect use and low tolerance for side effects.

Family planning discontinuation exposes women to the risk of unplanned pregnancy. Likewise, incorrect use exposes women to the risks of method failure and hence an unplanned pregnancy. Poor quality of care and discontinuation affect individual users. Yet, poor quality of care also affects others with whom users associate, and given that their dissatisfaction and likely failure to control fertility may be communicated to others, thereby harming the reputation of both the program and the methods provided.

A two-phase operations research study was launched in Egypt in early 2000 with the goal of demonstrating how improving the quality of client-provider interaction could be achieved in large health care systems, specifically in relation to family planning. The study was designed to explore how CPI improvements could enhance family planning knowledge, method continuation rates, client satisfaction and achievement of fertility goals. This study forms part of a global initiative conducted in comparable fashion in two other countries, Peru (León et al. 2003) and Uganda (Okullo et al. 2003). Reasonably comparable intervention packages, study designs and data collection tools have been used for this study concurrently in its three sites. 


\section{RESEARCH QUESTIONS}

The CPI study in Egypt has been designed to answer the following five research questions:

1. Can measurable improvements be made in client-provider interaction by introducing practical systems-oriented, provider-oriented, and client-oriented interventions?

2. If client-provider interactions are improved, will there be measurable improvements in: (a) women's knowledge about available contraceptive choices; (b) women's satisfaction with contraception; (c) continued use of any method; (d) women's ability to obtain their preferred method (unless there is clear contraindication); (e) correct use of the chosen method; (f) prompt switching to another method; (g) women's ability to achieve their fertility goals or reproductive intentions (to delay a first birth, to space or to limit pregnancies); (h) increased numbers of new and continuing clients attending the clinic; and (i) a more diverse method mix in family planning clinics?

3. What is the impact of the intervention package on the job satisfaction of providers?

4. What are the costs of the various components of the intervention (such as training, technical assistance, additional monitoring, and client visits)?

5. Do the costs of family planning visits increase, and if so, by how much? 


\section{CONCEPTUAL FRAMEWORK}

The conceptual framework guiding the design of this two-phase study is shown in Figure 1. It is assumed that a comprehensive intervention that addresses system-related, provider-related, and client-related factors will lead to positive changes in providers' technical knowledge and attitudes about family planning counseling, as well as provider motivation. Changes in the supervisory system will also help maintain a more client-centered interaction with clients. All these factors would then ultimately lead to the achievement of outcome variables at client, provider and clinic levels. The social context is also expected to exert some influence on the outcome variables in addition to program variables.

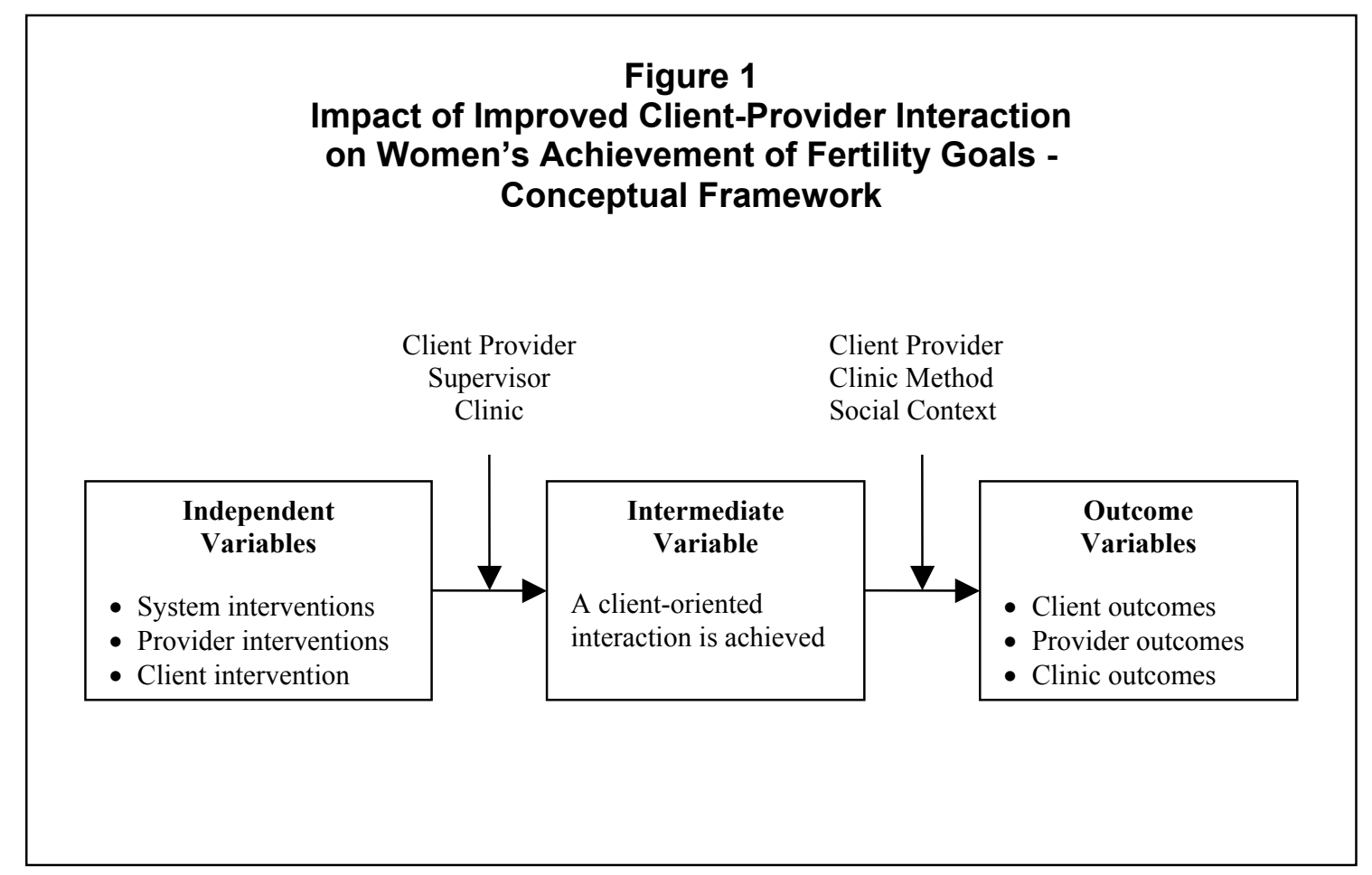

\section{STUDY DESIGN}

The study used two quasi-experimental designs. For research questions (1), (3), and (5), the study used the pre-test, post-test non-equivalent control group design. Clinics included in the study were randomly assigned as intervention or control clinics. Intervention clinics received the above-mentioned comprehensive intervention package for a period of six months. Clientprovider relations were measured in the two groups of clinics before the intervention (baseline) and immediately after the intervention (post-test) in order to capture behavioral changes. The following were also measured at baseline and immediately post-intervention: providers' knowledge and attitudes, and improved client-provider interaction; and use of each provider's time. The impact of the intervention on clinic outcomes such as client load was ascertained from service statistics. 
For research question (4), a special study on cost components was conducted. Cost data were collected and transferred into Excel ${ }^{\circledR}$ spreadsheets. Cost estimates for carrying out the intervention were derived.

Research question (2) was examined through Phase II of the study (the present study) in which a cohort of new family planning acceptors was enrolled and followed-up for a period of 13 months after the index visit. Client outcomes were measured at seven and 13 months through home interviews.

Variables: The intervention comprising its three components constitutes the independent variable. The impact of the intervention on providers' knowledge, attitudes, and improved client-provider interaction (both process and content) constitute the intermediate variables of the study. The ultimate dependent or outcome variables are: (a) client acheivement of fertility goals; (b) changes in client knowledge and satisfaction with services and family planning methods; (c) changes in continued use of any method; (d) changes in correct use; (e) changes in the interval between methods used; (f) changes in client load; and (g) changes in provider job satisfaction. Intervening variables include client, provider, clinic, and method characteristics.

\section{OVERVIEW OF PHASE I OF THE CPI STUDY}

\section{The Study Sample}

Four governorates were selected from Lower Egypt based on the following selection criteria: highest contraceptive discontinuation rate; and lowest contraceptive prevalence rate. These governorates were matched and randomly assigned to experimental and control groups. Two districts were selected at random from each governorate, for a total of eight districts in the two study groups. Within each district, six facilities were selected with: (a) a minimum quality score of 95 percent based on the MOHP standard quality checklist developed for its Gold Star Clinics; (b) a minimum monthly caseload of 20 new users; (c) urban and rural representation; and (d) representation of all types of facilities. Thus, a total of 48 facilities were included in the study for both study groups.

\section{The Baseline and Post-test}

The study baseline was a cross-sectional survey conducted in the study sites. It was undertaken during the period October - November 2000. It employed four data collection tools:

- Structured interviews with service providers (physicians, nurses, counselors and social workers).

- Structured observations of complete family planning sessions (counseling and clinical services).

- Client exit interviews with new and returning family planning clients.

- Selected service statistics from the twelve months preceding the baseline survey.

In addition, the baseline included observations of providers' use of time and collection of data on the cost of the intervention. The instruments provided data on a wide range of indicators related 
to the quality of family planning services provided, providers' knowledge, attitudes and practices, as well as job satisfaction. They also provided data on clients' perceptions of interaction with service providers, knowledge about family planning methods, and satisfaction with services received.

Another cross-sectional survey (post-test) was conducted after launching all activities of the study intervention in order to measure the intervention's impact. This survey employed the same data collection instruments and was conducted during the period of July - August 2001.

The post-test study findings reflected positive changes in clinic physical preparedness levels as well as in some indicators on providers' technical knowledge and attitudes towards family planning counseling. Clinical practices of providers in intervention clinics were also improved compared with the control clinics. Positive changes were also noted in several aspects of clientprovider interaction (CPI) in intervention clinics. In sum, the study results showed that improved CPI in the intervention group was associated with a number of positive outcomes for clients, providers, and clinics.

Several aspects of the knowledge, attitudes and practices of the providers in the control group remained unchanged between pre- and post-test, while other aspects deteriorated considerably in the post-test. Also, attitudes of providers in the control group became less client-oriented in the post-test compared with the pre-test. Furthermore, the interpersonal behavior of physicians and nurses in the control group deteriorated in the post-test compared with the pre-test (SPAAC 2002).

\section{THE PRESENT STUDY: PHASE II OF THE CPI STUDY}

\section{Study Design}

Phase II was a panel study in which clients who qualified for inclusion and who visited the study sites during the data collection period of the post-test survey (the index visit) were followed-up through home interviews at seven and 13 months following the index visit. This provided data on family planning continuation rates at 6 and 12 months, following improved CPI.

The case definition for inclusion in this panel study included new clients who were both observed and interviewed upon exit from the index visit, and who were starting a new episode of family planning use at the study sites during this visit with the intention of postponing pregnancy for at least 12 months. Women who qualified for the panel study include clients who visited the clinic to obtain a method for the first time, to re-use a method after a period of six months of non-use, or to switch to another method. 


\section{Client Outcome Variables}

For Phase II of the study, the principal variables of interest are listed below with a brief statement of their operationalization.

\author{
Improved client knowledge \\ about available contraceptive \\ options and about received \\ method
}

Method efficacy, how to use the method, duration of effectiveness, potential side effects, management of side effects. Each of the above items will receive a score of 1 if the client knows it and a score of 0 if she does not. A total knowledge score will be computed for each client.

This variable will be coded as a dichotomous variable (correct use / incorrect use). During home follow-up interviews, each woman will be asked questions to ascertain if she knows how to correctly use her contraceptive method. Data collectors will be trained on such aspects and will be given written materials describing correct use of all family planning methods.

\footnotetext{
Prompt switching
}

A client will be considered a prompt switcher if there is no method-free interval between two contraceptive methods, if she did not have sex during that method-free interval or if she used rhythm or withdrawal during the methodfree period.

\begin{tabular}{l} 
Client satisfaction with \\
received method \\
\hline Client satisfaction with services \\
at the clinic
\end{tabular}

A satisfaction index will be developed and will include concern about potential side effects, perceived method effectiveness, expected husband's approval of method, and perceived convenience of use.

A

A satisfaction score will be computed for each client that measures several aspects of client satisfaction (satisfaction with providers' counseling skills, providers' technical competence, waiting time and cost of service).

Ability to achieve reproductive
intentions

Acc

According to the case definition, women enrolled in this panel study do not
wish to have any children at least in the following 12-month period. Women who do not change their reproductive intentions during the following 12-month period, yet become pregnant during periods of family planning method use or non use, will be considered as unable to achieve reproductive intentions.

Continued use of family
planning

A client will be considered a continuer if she reports using any modern family planning method at the time of the interview (regardless of the method she received at the clinic). A distinction will be made between two types of discontinuers: those that imply a reduced need for contraception (infrequent sex, partner away, wish to conceive) and all other reasons for discontinuation (contraceptive failure, husband's disapproval, as it is assumed that counselors should have done a better job anticipating husband's negative reactions, experience or fear of side effects). The latter will be considered "qualityrelated reasons". 


\section{Study Sample \\ Seven month follow-up home interviews}

According to the Phase I post-test study findings, the number of women who qualified for inclusion in this panel study was 195 for the experimental group and 160 for the control group. In addition, a sample of new clients who were only interviewed upon exit from the clinic (i.e., their consultations were not observed), yet meet the case definition for inclusion in the panel study, were enrolled in the panel study in order to increase the statistical power and compensate for potential loss to follow-up cases.

This latter selection was done proportional to the size of each district in both the intervention and control governorates. Table 1 shows the final sample size adopted in the seven month and 13 month follow-up home visits.

A sample size of 300 in each of the study groups yielded a power of 0.96 given an alpha value of 0.05 , and an anticipated 10 percentage point difference in continuation rates between the two study groups. It was initially Table 1: Sample size, seven month and 13 month follow-up home visits

\begin{tabular}{|l|c|c|c|}
\hline & Intervention & Control & Total \\
\hline & \multicolumn{3}{|c|}{$\begin{array}{c}\text { Seven month follow-up home } \\
\text { interviews }\end{array}$} \\
\hline Observed & 170 & 146 & 316 \\
\hline Non-observed & 130 & 154 & 284 \\
\hline Total & 300 & 300 & 600 \\
\hline & 13 month follow-up home interviews \\
& 169 & 144 & 313 \\
\hline Observed & 126 & 151 & 277 \\
\hline Non-observed & 295 & 295 & 590 \\
\hline Total & \multicolumn{3}{|}{} \\
\hline
\end{tabular}
assumed that loss to follow-up would be within 20 percent on average. However, in the implementation of the seven month follow-up interviews, only 10.9 percent of the observed cases were lost to follow-up. These were randomly replaced during field operations following procedures previously established. The new cases were drawn from the same pool of eligible women in the sampling frame who were interviewed upon exit in the post-test, but whose consultations were not observed. For the non-observed cases, replacement was done by including the woman listed next to each selected case. For the observed cases, replacement was done by including the woman (interviewed only upon exit) listed next to the identified observed case. It should be noted here that, according to the study's sample design (please refer to Phase I report under study sample, SPAAC 2002), the population of clients who qualified for the exit interviews included all new and returning clients who visited the study clinics during the recruitment period (one month). The first 30 clients who visited each study clinic during the recruitment period were interviewed upon exit. Among them, 10 consultations between clients and physicians or nurses per clinic were observed for quality of client-provider interaction. 


\section{Thirteen month follow-up home interviews}

A second follow-up interview for the same women was undertaken 13 months after the index visit. There were only 10 cases (1.6\%) lost to follow-up (see Table 1). Reasons for loss to follow-up included: refusal, divorce, husband's death, moving to a different neighborhood or village, and respondent's absence despite repeated home visits. These cases were not replaced. Data collectors made great efforts during the seven month follow-up visits to identify and reach eligible women for home interviews, which made it easier to locate women in the 13 month follow-up home visit.

\section{Home Interview Instrument}

A questionnaire was designed to collect data from the client during follow-up home interviews. The questionnaire included socioeconomic indicators on the woman, her husband and the household, as well as reproductive health indicators, and detailed data on client outcome indicators.

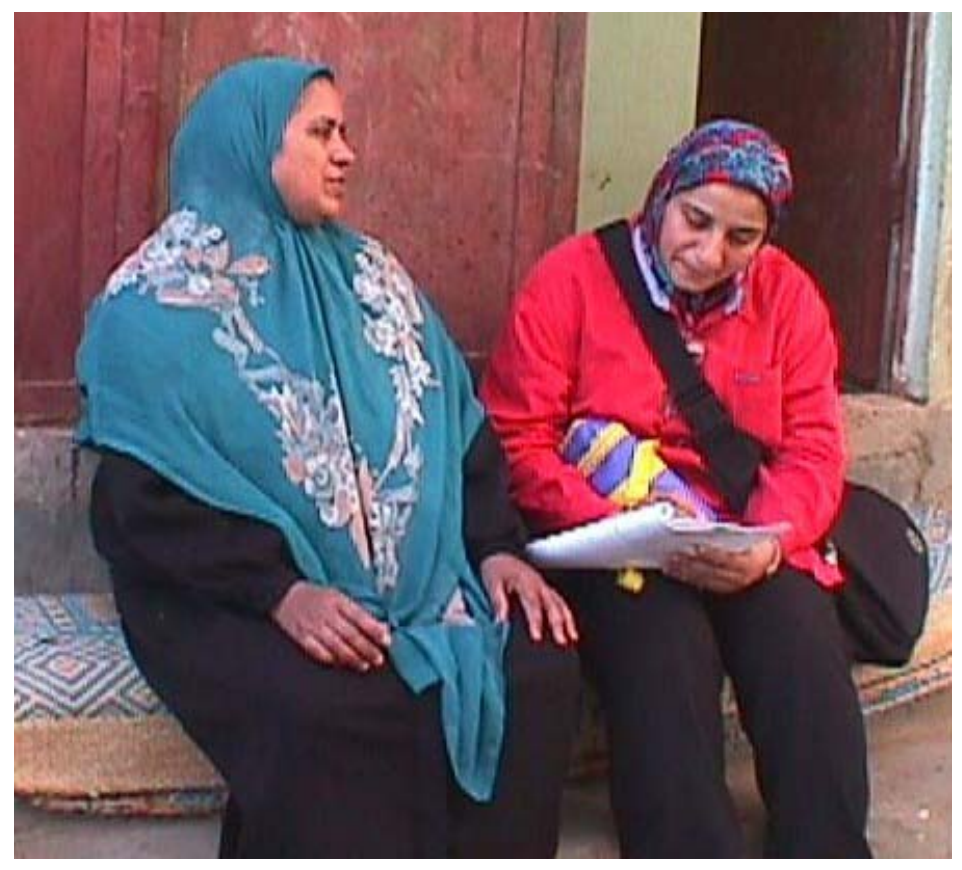

\section{Pilot Testing of the Study Instrument}

The research instrument was pre-tested with a small number of clients who were not included in the study. The instrument was revised as needed based on the findings of the pilot test. Enough copies of the instrument were printed for use in both training of data collectors and subsequent home interviews.

\section{Data Collection Procedures Seven month follow-up interviews (March 2002)}

Experienced female interviewers were recruited to conduct the seven month follow-up home interviews, four for each governorate. Also, four qualified field supervisors were also recruited, one for each governorate, to assist in locating respondents' homes, review completed questionnaires in the field, and give regular guidance and feedback to interviewers. Interviewers were recruited and trained in Cairo but stayed in the field for the whole data collection period in order to have flexible time for conducting home interviews as appropriate.

The interviewers and field supervisors attended a five-day training course with a main field organizer and other relevant research staff at the Cairo Demographic Center (CDC), the implementing agency of the study. They were supplied with the Field Work Instructions Manual, the questionnaires, and rosters with the names of clients to be contacted, the husbands' names, addresses, name of the index clinic, and date of the index interview from Phase I of the study. 
These rosters also included all the non-observed clients from the selected sample, in order to replace the cases lost to follow-up with observed clients eligible for interviews. Interviewers were instructed to make up to three home visits before considering the client as a case lost to follow-up. Cases lost to follow-up were replaced randomly according to procedures established by the research team. Careful review of the final study instrument, role playing, as well as issues of informed consent and confidentiality were comprehensively reviewed during the training.

\section{Thirteen month follow-up interviews (September 2002)}

The same field teams that conducted the seven month follow-up interviews conducted the 13 month interviews. All teams attended a refresher training course at CDC in September 2002. They were supplied with the modified Field Work Instructions Manual, the modified questionnaires, and new rosters with the names of clients to be interviewed, the addresses and phone numbers of many of them, and the name of the index clinic. The interviewers were again instructed to follow-up home visits three times before considering the client as a case lost to follow-up, with no replacement.

\section{Data Entry and Analysis}

Data collected through home interviews was processed at CDC. An analysis plan was developed, and data analysis was conducted using SPSS version 11. Different statistical tests were used to compare indicators from the intervention and control groups. The type of test was determined by the type of variable. For dichotomous variables, the chi-square test was used to test the significance of differences. The two levels (yes and no) of the variable were considered in order to have a $2 \times 2$ contingency table. The null hypothesis $(\mathrm{H} 0)$ and the alternative hypothesis ( $\mathrm{H} 1)$ for these types of variables were:

H0: The intervention had no impact (i.e., the percentage distribution of the variable in the intervention group is equal to the percentage distribution of the same variable in the control group).

H1: The intervention had an impact (i.e., the percentage distribution of the variable in the intervention group is not equal to the percentage distribution of the same variable in the control group).

Although the Z-test (standard normal distribution) could be used in the dichotomous variables, the chi-square test was used as it is easier to apply using SPSS (the two tests are equivalent). For other categorical variables, the chi-square test was also applied. The hypotheses were the same for the dichotomous variables. Other nonparametric tests can be used especially for ordinal categorical data, but chi-square is more powerful in the case of having a large sample. For continuous variables (interval or ratio) the t-test was used to compare the means of two independent samples.

Level of significance: Two levels of significance were considered: alpha $=0.05$ and alpha $=0.01$. If the two-tailed level of significance as appeared in the SPSS output is smaller than alpha, then the difference is considered significant at this level. The equivalence of variances was considered in this case. The two levels of significance are marked by “*” for 0.05 and "**” for 0.01 at the bottom of each table. 
Life table analysis was also used in this study to estimate cumulative continuation rates of family planning method use. During the seven month and the 13 month home follow-up interviews, women in both study groups were asked to report on all episodes of contraceptive use between the time of the index visit and the follow-up home visits. The study instrument included a special section with a number of questions on each method used since the index visit, duration of use, periods of non-use, and reasons for discontinuing use of each method. This information was used to calculate life table cumulative continuation rates since the index visit, using segments of use of each method used.

The study also conducted multiple (logistic) regression analysis with contraceptive use as the dependent variable in order to analyze factors that influence contraceptive use (discontinuation versus continuation). Several models were developed; each included a number of independent variables that were expected to have some influence on continuation. The independent variables used in the analysis were clustered into five groups and used in each model. These included site characteristics, clients' socio-demographic characteristics, reproductive characteristics, client satisfaction, and knowledge related to methods. For each model, logistic regression analysis and stepwise logistic regression analysis were performed. Variables that were found to be significant in each model were included in the final model. This procedure was done for both seven and 13 month follow-up interviews.

The independent variables that were included in the final model of the seven month follow-up visit were:

- Marital status

- Intention to have more children (yes $=1$, no $=0$ )

- Previous child loss (yes $=1$, no $=2$ )

- Intervention versus control

- Knowledge score of correct use of method

- Knowledge score of family planning method used

- Still visiting the same clinic (yes $=1$, no=2)

- Method satisfaction score

The independent variables that were included in the final model of the 13 month follow-up interview were:

- Intention to have more children (yes $=1, \mathrm{no}=0$ )

- Previous child loss (yes $=1$, no $=2$ )

- Intervention versus control

- Knowledge score of correct use of method

- Knowledge score of family planning method used

- Still visiting the same clinic (yes $=1, \mathrm{no}=2$ )

- Method satisfaction score

- Husband's occupation

Multiple regression analyses (linear and logistic) were also done to determine what factors might have influenced each of the above independent variables significantly related to contraceptive 
use. These analyses were also performed through development of several models. However, fewer steps were needed in this case as there were not as many independent variables included in each model.

The dependent variables included for the seven month follow-up visit for which some independent variables were found to have significant influence were:

- Method satisfaction score at index visit

- Knowledge of correct use at index visit

- Knowledge of the method used at index visit

- Still visiting the same clinic (logistic regression analysis)

For the case of the 13 month follow-up interview, the following dependent variables were considered:

- Satisfaction with the contraceptive method at index visit

- Knowledge score of method received at index visit

Lastly, qualitative data analysis was conducted to provide some insights to the underlying reasons for discontinuing method use, and thus exposure to pregnancy among women of the intervention group. These discontinuers had reported in the index visit that they did not plan for a birth in the following 12 months. In-depth home interviews were conducted with women who became pregnant in the intervention group. An interview guide was designed and used for this purpose.

\section{Protection of Research Participants}

Clients were not required to undergo any physically invasive procedures, beyond those mandated by national norms for family planning care (e.g., pelvic exam before IUD insertion). The family planning methods are those provided by the Egyptian family planning program. The methods and clinical procedures used are those specified in Egypt's Ministry of Health and Population national guidelines and norms.

Clients' consent was sought during the exit interviews following the index visit of study Phase I. The consent statement made it clear to clients that their participation was voluntary and that they could withdraw during any part of the study (e.g., refuse to respond to a question if they feel uncomfortable). At the time of conducting home interviews, clients were again asked to give consent for the home interview, despite previously consenting to it during the index visit.

Interviewers were trained to handle topics in a sensitive fashion and to be aware when clients became uncomfortable in participating. The careful application of selection characteristics and training of interviewers for this study were essential to avoiding risks that might be posed to clients. All data collectors were females and were monitored on a continual basis by the field supervisor.

Procedures to ensure confidentiality were strictly observed. For the home follow-up interview, clients were given the choice of having it at the clinic rather than at their home. If the interview 
took place at the client's home, the interviewer made sure that privacy was maintained during the interview. Clinic interviews were held in a private area to ensure that clinic staff or other clients did not overhear the conversation.

No personal or clinic identifiers were recorded on interview schedules; rather, identification code numbers were used. All data were kept separately from identifying information, and both were stored in locked cabinets in the research office. Access to the data was limited to the senior research staff. Clinical staff did not have access to the data.

\section{FINDINGS}

\section{Women's Background Characteristics}

Table 2 shows selected demographic and socio-economic characteristics for women in the two study groups. Women in both groups were very close with regard to age (mean $=29.5$ years) and their husbands' age (mean $=36$ years). However, women in the intervention group were slightly less educated (mean years of schooling was 9.4 versus 10.0 for the control, $\mathrm{p}<0.01$ ). On the other hand, husbands of women in the intervention group were better educated (mean years of schooling 10.3 versus 9.6 for the control group, $p<0.01$ ). About 90 percent of women in the intervention group lived in rural areas, while 81 percent of women in the control group lived in rural areas $(\mathrm{p}<0.05)$.

A composite indicator for socio-economic status of the household was developed with a scale of 1-14, reflecting household possession of a number of appliances as well as housing conditions (see score 1 in Appendix I). Findings show a mean value of 8.6 for women in the intervention group compared with 8.1 for the control group $(\mathrm{p}<0.01)$. 
Table 2: Selected demographic and socio-economic characteristics for women in the intervention and control groups, at seven month follow-up visit

\begin{tabular}{|c|c|c|}
\hline Background Characteristics & $\begin{array}{l}\text { Intervention } \\
\text { Group \% } \\
\mathbf{N}=300\end{array}$ & $\begin{array}{c}\text { Control Group \% } \\
N=300\end{array}$ \\
\hline $\begin{array}{l}\text { Women's age } \\
\text { less than } 25 \\
25-34 \\
35 \text { or more } \\
\text { Mean age } \\
\text { Standard Deviation (S.D.) }\end{array}$ & $\begin{array}{l}30.3 \\
43.0 \\
26.7 \\
29.6 \\
(7.4) \\
\end{array}$ & $\begin{array}{l}26.0 \\
49.7 \\
24.3 \\
29.5 \\
(6.6) \\
\end{array}$ \\
\hline $\begin{array}{l}\text { Type of residence } \\
\text { Urban } \\
\text { Rural }\end{array}$ & $\begin{array}{c}10.3 \\
89.7^{*}\end{array}$ & $\begin{array}{l}19.0 \\
81.0\end{array}$ \\
\hline $\begin{array}{l}\text { Women's education } \\
\text { No schooling/less than primary } \\
\text { Primary } \\
\text { Preparatory } \\
\text { High school/university } \\
\text { Mean number of years of school } \\
\text { (S.D.) }\end{array}$ & $\begin{array}{l}32.0 \\
20.0 \\
12.7 \\
35.3 \\
9.4^{* *} \\
(4.1)\end{array}$ & $\begin{array}{c}40.7 \\
14.7 \\
4.0 \\
40.6 \\
10.0 \\
(3.6)\end{array}$ \\
\hline $\begin{array}{l}\text { Women's work status } \\
\text { Currently working } \\
\text { Among currently working, percent working outside home }\end{array}$ & $\begin{array}{l}12.3 \\
83.8\end{array}$ & $\begin{array}{l}18.7 \\
94.6\end{array}$ \\
\hline $\begin{array}{l}\text { Husband's current age } \\
\text { less than } 25 \\
25-34 \\
35 \text { or more } \\
\text { Mean age } \\
\text { (S.D.) }\end{array}$ & $\begin{array}{c}6.7 \\
42.0 \\
51.3 \\
36.0 \\
(8.5) \\
\end{array}$ & $\begin{array}{l}3.7 \\
41.9 \\
54.4 \\
36.0 \\
(8.0)\end{array}$ \\
\hline $\begin{array}{l}\text { Husband's education } \\
\text { No schooling/less than primary } \\
\text { Primary } \\
\text { Preparatory } \\
\text { Secondary/university } \\
\text { Mean number of years of school } \\
\text { (S.D.) }\end{array}$ & $\begin{array}{c}24.6 \\
17.7 \\
16.0 \\
41.7 \\
10.3^{* *} \\
(3.8)\end{array}$ & $\begin{array}{c}28.8 \\
19.1 \\
10.7 \\
41.4 \\
9.6 \\
(3.8)\end{array}$ \\
\hline $\begin{array}{l}\text { Husband's occupation } \\
\text { Professional } \\
\text { Services } \\
\text { Farming } \\
\text { Skilled labor } \\
\text { Unskilled labor }\end{array}$ & $\begin{array}{l}23.2 \\
21.5 \\
18.5 \\
17.8 \\
18.9\end{array}$ & $\begin{array}{l}12.8 \\
19.5 \\
38.5 \\
17.1 \\
12.1\end{array}$ \\
\hline $\begin{array}{l}\text { SES (a) } \\
\text { Low }(1-7) \\
\text { Medium (8-9) } \\
\text { High }(10+) \\
\text { Mean SES }\end{array}$ & $\begin{array}{l}30.8 \\
36.5 \\
32.8 \\
8.6^{\star *}\end{array}$ & $\begin{array}{c}39.3 \\
28.3 \\
32.3 \\
8.1\end{array}$ \\
\hline
\end{tabular}

${ }^{*} p<0.05,{ }^{* *} p<0.01$

(a) A composite indicator for socio-economic status of the household. It ranges between 0-14 (see description of score 1 in Appendix I). 
Table 3 shows selected reproductive history characteristics for the two study groups. Women in the intervention group married somewhat earlier (mean age $=18.8$ ) than women in the control group (mean age $=19.4$ ), and the difference is statistically significant $(\mathrm{p}<0.01)$. Achieved and desired fertility indicators were higher among women in the intervention group than the control group. The mean number of living children was 2.9 for the intervention group compared with 2.7 for the control group $(\mathrm{p}<0.05)$. Also, women in the intervention group experienced more child deaths on average ( 0.3 versus 0.1$)$ and had more living girls (1.5 versus 1.3$)$ than women in the control group, respectively; the latter differences are statistically significant $(\mathrm{p}<0.05)$.

Table 3: Selected reproductive health characteristics for women in the intervention and control groups at seven month follow-up visit

\begin{tabular}{|l|c|c|}
\hline Reproductive Characteristics & $\begin{array}{c}\text { Intervention } \\
\text { Group } \% \\
\mathbf{N}=\mathbf{3 0 0}\end{array}$ & $\begin{array}{c}\text { Control Group \% } \\
\mathbf{N}=\mathbf{3 0 0}\end{array}$ \\
\hline Mean age at first marriage & $18.8^{* *}$ & 19.4 \\
(S.D.) & 3.2 & 3.3 \\
\hline Mean no. of children ever born & $3.2^{*}$ & 2.8 \\
(S.D.) & 2.0 & 1.5 \\
\hline Mean no. of living children & $2.9^{*}$ & 2.7 \\
(S.D.) & $(1.61)$ & $(1.3)$ \\
Mean no. of living boys & 1.5 & 1.4 \\
(S.D.) & $(1.19)$ & $(0.9)$ \\
Mean no. of living girls & $1.5^{*}$ & 1.3 \\
(S.D.) & $(1.17)$ & $(1.1)$ \\
\hline Want more children (\% yes) & 34.0 & 27.3 \\
\hline Spacing duration before next child & $\mathrm{N}=102$ & $\mathrm{~N}=82$ \\
Less than one year & 3.0 & 7.3 \\
From one to less than two years & 14.7 & 15.8 \\
Two years or more & 73.5 & 73.2 \\
Up to God & 8.8 & 3.7 \\
\hline Mean no. of additional children desired in the future & $0.46^{*}$ & 0.34 \\
(S.D.) & $(0.7)$ & $(0.6)$ \\
\hline Family planning method received at index visit & & \\
IUD & 60.3 & 61.7 \\
Injectables & 23.7 & 31.7 \\
Pills & 14.3 & 6.0 \\
Others & 1.7 & 6.0 \\
\hline
\end{tabular}

${ }^{*} p<0.05,{ }^{* *} p<0.01$

Slightly more women in the intervention group wanted to have additional children compared with the control group (34\% versus $27 \%$, not significant). Among those women, the mean number of additional children desired in the future was also higher among women in the intervention group as compared to women in the control group ( 0.46 versus 0.34$)$, and the difference was significant $(\mathrm{p}<0.05)$.

Data on the family planning method received at the index visit indicates that approximately equal proportions of women in both study groups received an IUD (about 61\%). Fewer women in the intervention group received injectables compared with women in the control group ( $24 \%$ versus $32 \%$, respectively), while more women in the intervention group received the pill (14\% versus $6 \%$ ). None of the differences in family planning methods received reached significance. 
Table 4 shows family planning methods used by women in both study groups at seven month and 13 month home follow-up interviews. Similar patterns as those indicated for the index visit are reported.

Table 4: Family planning methods use at seven and 13 month follow-up interviews

\begin{tabular}{|l|c|c|c|c|}
\hline \multirow{2}{*}{$\begin{array}{l}\text { Women currently using a } \\
\text { method (number) }\end{array}$} & \multicolumn{2}{|c|}{ Seven month interview } & \multicolumn{2}{c|}{$\mathbf{1 3}$ month interview } \\
\cline { 2 - 5 } Method currently used (\%) & $\mathbf{2 6 9}$ & $\mathbf{2 7 4}$ & $\mathbf{2 4 6}$ & $\mathbf{2 5 4}$ \\
\hline Pill & & & & \\
\hline IUD & 16.4 & 7.7 & 15.0 & 10.2 \\
\hline Injectable & 60.6 & 61.3 & 58.9 & 63.4 \\
\hline Norplant & 21.6 & 29.6 & 22.8 & 25.6 \\
\hline Condom & 0.4 & 0.7 & 0.8 & 0.4 \\
\hline Other & 0.6 & 0.7 & 0.8 & 0.0 \\
\hline
\end{tabular}

Differences are not significant

\section{Return visits to study clinics}

Providers at the intervention clinics received training on information that should be exchanged with clients during the counseling session. One item is the importance of making return visits to the clinic in the case of problems with method side effects that could not be tolerated. Also, women were instructed about the follow-up schedule of visits that should be made to the clinic. Tables 5-7 provide information on these aspects of contraceptive use.

Table 5: Percent of clients visiting index clinics for family planning services at seven and 13 months

\begin{tabular}{|c|c|c|c|c|}
\hline \multirow[b]{2}{*}{ Status } & \multicolumn{2}{|c|}{$\begin{array}{c}\text { Seven month interview } \\
\text { March } 2002 \\
\text { July } 2001 \text { - Feb. } 2002^{(1)}\end{array}$} & \multicolumn{2}{|c|}{$\begin{array}{l}13 \text { month interview } \\
\text { September } 2002 \\
\text { March - Sept. } 2002^{(2)}\end{array}$} \\
\hline & $\begin{array}{c}\text { Intervention } \\
\mathrm{N}=300\end{array}$ & $\begin{array}{l}\text { Control } \\
\mathrm{N}=300\end{array}$ & $\begin{array}{c}\text { Intervention } \\
\mathrm{N}=295\end{array}$ & $\begin{array}{c}\text { Control } \\
\mathrm{N}=295\end{array}$ \\
\hline Yes & $\begin{array}{c}51.7 \\
N=155\end{array}$ & $\begin{array}{c}52.7 \\
N=158\end{array}$ & $\begin{array}{c}46.1 \\
N=136\end{array}$ & $\begin{array}{c}46.8 \\
N=138\end{array}$ \\
\hline $\begin{array}{l}\text { According to follow-up schedule } \\
\text { According to follow-up schedule and }\end{array}$ & 36.1 & 40.5 & 44.8 & 42.1 \\
\hline $\begin{array}{l}\text { when necessary } \\
\text { When necessary }\end{array}$ & $\begin{array}{l}11.6 \\
52.3\end{array}$ & $\begin{array}{l}17.1 \\
42.4\end{array}$ & $\begin{array}{l}14.0 \\
41.2\end{array}$ & $\begin{array}{l}21.7 \\
36.2\end{array}$ \\
\hline No & $\begin{array}{c}48.3 \\
N=145\end{array}$ & $\begin{array}{c}47.3 \\
N=142\end{array}$ & $\begin{array}{c}53.9 \\
N=159\end{array}$ & $\begin{array}{c}53.2 \\
N=157\end{array}$ \\
\hline
\end{tabular}

*At least one visit

(1) The period between index visit and seven month follow-up visit

(2) The period between seven month and 13 month follow-up interview

Only slightly more than one-half of women in the intervention and control clinics made return visits to the clinic within seven months of the index visit (Table 5). The majority of those women made these visits when faced with problems of method side effects, or when they wanted to switch methods. More women in the intervention clinics (52\%) than in the control clinics (42\%) 
visited the clinics for these reasons; however the difference was not significant. Slightly less than one-half of women made return visits to the study clinics between seven and 13 months of the index visits, and differences between the groups were not significant.

At the first follow-up home interview, the majority of women reported making two visits to the clinic (Table 6). At the 13 month follow-up home interview, however, the majority of women in the intervention group reported making one visit, while the majority of women in the control group reported making two visits. The mean number of visits for women in the intervention group is 2.1 as compared with 1.9 visits for women in the control group, and the difference was statistically significant $(\mathrm{p}<0.01)$.

Table 6: Percent distribution of clients who reported visiting the index clinic, by number of visits

\begin{tabular}{|l|c|c|c|c|}
\hline \multirow{2}{*}{ No. of visits } & \multicolumn{2}{|c|}{$\begin{array}{c}\text { Seven month interview } \\
\text { March 2002 }\end{array}$} & \multicolumn{2}{c|}{$\begin{array}{c}\text { 13 month interview } \\
\text { September 2002 }\end{array}$} \\
\cline { 2 - 5 } & July 2001 - Feb. 2002 & \multicolumn{2}{c|}{$\begin{array}{c}\text { March - Sept. 2002 } \\
\text { (2) }\end{array}$} \\
\hline 1 & $\begin{array}{c}\text { Intervention } \\
\mathbf{N = 1 4 8}\end{array}$ & $\begin{array}{c}\text { Control } \\
\mathbf{N}=\mathbf{1 5 6}\end{array}$ & $\begin{array}{c}\text { Intervention } \\
\mathbf{N}=\mathbf{1 3 6}\end{array}$ & $\begin{array}{c}\text { Control } \\
\mathbf{N}=\mathbf{1 3 7}\end{array}$ \\
\hline 2 & 31.8 & 34.0 & 46.3 & 35.8 \\
\hline 3 & 50.0 & 45.5 & 28.7 & 45.3 \\
\hline $4-8$ & 10.1 & 14.1 & 12.5 & 13.1 \\
\hline $\begin{array}{l}\text { Mean number of } \\
\text { visits }\end{array}$ & 8.2 & 6.4 & 12.4 & 5.8 \\
\hline
\end{tabular}

${ }^{* *} \mathrm{p}<0.01$

(a) Other cases do not know number of visits

(1) The period between index visit and seven month follow-up visit

(2) The period between seven month and 13 month follow-up interview

Women who did not make any return visits to the study clinics were asked about their reasons (Table 7). Few of them reported reasons related to poor quality of care provided at the clinic (e.g., doctor is not good or not available, poor treatment). Also few women reported that the method was not available. The majority of women (between two-thirds to three-fourths) reported that they were comfortable with using their long-acting method and, thus, they saw no reason to visit the clinic. The second most commonly reported reason for not making return visits to the clinic was stopping using any method. Additionally, about one-tenth of the women shifted to other sources for their method supply and, therefore, reported making no return visits to the clinic. Differences in these patterns between intervention and control groups were small and not significant. 
Table 7: Reasons cited for stopping clinic visits

\begin{tabular}{|l|c|c|c|c|}
\hline \multirow{2}{*}{} & \multicolumn{2}{|c|}{ Seven month interview } & \multicolumn{2}{c|}{$\mathbf{1 3}$ month interview } \\
\cline { 2 - 5 } & $\begin{array}{c}\text { Intervention } \\
\mathbf{N = 1 4 5}\end{array}$ & $\begin{array}{c}\text { Control } \\
\mathbf{N = 1 4 2}\end{array}$ & $\begin{array}{c}\text { Intervention } \\
\mathbf{N = 1 5 9}\end{array}$ & $\begin{array}{c}\text { Control } \\
\mathbf{N = 1 5 7}\end{array}$ \\
\hline \multirow{2}{*}{ Clinic related reasons ${ }^{\mathrm{a}} \%$} & 3.4 & 3.5 & 1.3 & 2.5 \\
& $\mathrm{~N}=5$ & $\mathrm{~N}=5$ & $\mathrm{~N}=2$ & $\mathrm{~N}=4$ \\
\hline \multirow{2}{*}{ Client related reasons \% } & 96.6 & 96.5 & 98.7 & 97.5 \\
& $\mathrm{~N}=140$ & $\mathrm{~N}=137$ & $\mathrm{~N}=157$ & $\mathrm{~N}=153$ \\
\hline Comfortable with long-acting method & 72.1 & 71.5 & 61.8 & 68.6 \\
\hline Stopped using any method & 17.1 & 14.6 & 22.3 & 16.3 \\
\hline Get supply from other source & 9.3 & 10.9 & 14.0 & 14.4 \\
\hline Switched to traditional method & 0.7 & 1.5 & 1.9 & 0.7 \\
\hline Other & 0.7 & 1.5 & -- & -- \\
\hline
\end{tabular}

${ }^{\mathrm{a}}$ Includes doctor is not available/not good.

Almost all women who stopped visiting the clinics reported that none of the clinic staff visited them at home to investigate reasons for dropping out (Table 8). This finding is unexpected, since the clinic outreach persons (social workers) should make some follow-up home visits to investigate reasons for not making return visits. About 10 percent of women from intervention clinics indicated that a clinic staff member visited them at home to discuss reasons for their drop out. Most of the home visits to these women took place within two to six months of drop out (data not shown).

Table 8: Percent of women reporting a visit by clinic staff after dropping out of the clinic

\begin{tabular}{|l|c|c|c|c|}
\hline & \multicolumn{2}{|c|}{ Seven month interview } & \multicolumn{2}{c|}{$\mathbf{1 3}$ month interview } \\
\hline $\begin{array}{l}\text { Were you visited by clinic } \\
\text { staff? }\end{array}$ & $\begin{array}{c}\text { Intervention } \\
\mathbf{N}=\mathbf{1 4 5}\end{array}$ & $\begin{array}{c}\text { Control } \\
\mathbf{N}=\mathbf{1 4 2}\end{array}$ & $\begin{array}{c}\text { Intervention } \\
\mathbf{N}=\mathbf{1 5 9}\end{array}$ & $\begin{array}{c}\text { Control } \\
\mathbf{N}=\mathbf{1 5 7}\end{array}$ \\
\hline No & 95.9 & 97.2 & 89.3 & 99.4 \\
& $\mathrm{~N}=139$ & $\mathrm{~N}=138$ & $\mathrm{~N}=142$ & $\mathrm{~N}=156$ \\
\hline Yes & 4.1 & 2.8 & 10.7 & 0.6 \\
& $\mathrm{~N}=6$ & $\mathrm{~N}=4$ & $\mathrm{~N}=17$ & $\mathrm{~N}=1$ \\
\hline
\end{tabular}

\section{Client Outcome Indicators Improved clients' knowledge about available contraceptive options and about method received}

For each family planning method, women in both the intervention and control groups were asked one question regarding basic information related to that method (how the method works, correct use, potential side effects, management of side effects, or method efficacy). Table 9 shows that general knowledge of family planning methods was low in both study groups.

Women in both study groups knew more about the pill, the IUD, and the injectable (the methods most frequently used). Women in the intervention group knew more about how to use the pill compared with the control group (48\% versus $44 \%$ for the seven month follow-up, and $49 \%$ versus $47 \%$ at the 13 month follow-up, $\mathrm{p}<0.01$ ). Also, significant improvement was noted in the knowledge of the method that protects against STI (i.e., the condom) in the intervention group compared with the control group in both follow-up visits $(6 \%$ versus $2 \%$ for the seven month follow-up and $12 \%$ versus $5 \%$ at the 13 month follow-up, $p<0.01)$. Women in the control group 
were more likely to know that Norplant could provide protection from pregnancy for five years, and the differences were significant.

Table 9: General knowledge of family planning methods among women at seven month and 13 month follow-up interviews

\begin{tabular}{|c|c|c|c|c|}
\hline & \multicolumn{4}{|c|}{ Percent of women reporting the correct answer } \\
\hline & \multicolumn{2}{|c|}{ Seven month interview } & \multicolumn{2}{|c|}{13 month interview } \\
\hline & $\begin{array}{c}\text { Intervention } \\
\mathrm{N}=300\end{array}$ & $\begin{array}{l}\text { Control } \\
\mathrm{N}=300\end{array}$ & $\begin{array}{l}\text { Intervention } \\
\quad \mathrm{N}=\mathbf{2 9 5}\end{array}$ & $\begin{array}{c}\text { Control } \\
\mathrm{N}=295\end{array}$ \\
\hline How does the rhythm method work to avoid pregnancy? & 5.0 & 5.5 & $5.4^{* *}$ & 5.1 \\
\hline How are vaginal tablets used to prevent pregnancy? & 9.0 & 11.8 & 10.7 & 13.9 \\
\hline How are oral contraceptive pill used? & $48.0^{\star *}$ & 44.3 & $49.2^{\star *}$ & 46.6 \\
\hline $\begin{array}{l}\text { When should women receive each supply of } \\
\text { injectables? }\end{array}$ & 47.5 & 47.5 & 49.0 & 49.7 \\
\hline Where is the IUD inserted? & 47.5 & 47.7 & 49.2 & 49.7 \\
\hline What is the main consequence of the tubal ligation? & $25.3^{*}$ & 26.5 & 29.5 & 30.0 \\
\hline What is the method that can protect against STI? & $6.3^{* *}$ & 1.7 & $11.9^{\star *}$ & 5.1 \\
\hline $\begin{array}{l}\text { How many years does Norplant protect from } \\
\text { pregnancy? }\end{array}$ & 16.3 & $23.8^{\star *}$ & 21.7 & $26.6^{*}$ \\
\hline
\end{tabular}

${ }^{*} p<0.05,{ }^{* *} p<0.01$

Table 10 shows data on women's knowledge of criteria for LAM to be effective as a family planning method. The data indicate low knowledge of these criteria among women in both study groups. For the three basic criteria shown in the table, women in both study groups had very little information about two of them (i.e., maintaining exclusive breastfeeding up to 6 months postpartum and the importance of exclusive breastfeeding, with no supplementary food).

Table 10: Knowledge score ${ }^{a}$ of criteria for LAM to be effective as a family planning method

\begin{tabular}{|l|c|c|c|c|}
\hline \multirow{2}{*}{$\begin{array}{l}\text { Criteria for effective } \\
\text { LAM \% }\end{array}$} & \multicolumn{2}{|c|}{$\begin{array}{c}\text { Seven month } \\
\text { interview }\end{array}$} & \multicolumn{2}{c|}{$\mathbf{1 3}$ month interview } \\
\cline { 2 - 5 } & $\begin{array}{c}\text { Intervention } \\
\mathbf{N = 3 0 0}\end{array}$ & $\begin{array}{c}\text { Control } \\
\mathbf{N = 3 0 0}\end{array}$ & $\begin{array}{c}\text { Intervention } \\
\mathbf{N = 2 9 5}\end{array}$ & $\begin{array}{c}\text { Control } \\
\mathbf{N = 2 9 5}\end{array}$ \\
\hline $\begin{array}{l}\text { Breastfeeding up to 6 } \\
\text { months after delivery }\end{array}$ & 0.7 & 1.7 & 0.3 & 2.7 \\
\hline $\begin{array}{l}\text { Exclusive breastfeeding } \\
\text { (no supplementary food) }\end{array}$ & 4.7 & 2.3 & 2.7 & 0.7 \\
\hline No menstruation & 50.5 & $65.7^{* *}$ & 61.4 & $81.4^{* *}$ \\
\hline $\begin{array}{l}\text { Mean percent } \\
\text { knowledge score }\end{array}$ & $18.4^{*}$ & 23.2 & $21.1^{* *}$ & 27.5 \\
\hline
\end{tabular}

${ }^{* *} p<0.01, p<0.05$

${ }^{\text {a }}$ See description of Index 2 in Appendix I. 
Women in both study groups, however, had reasonable knowledge about the third criterion, that women should have no menstruation while breastfeeding for LAM to remain effective as a family planning method. Unexpectedly, more women in the control group than the intervention group were able to mention that criterion at both the seven month follow-up interview (66\% versus 51\%) and the 13 month follow-up interview (81\% versus $61 \%$ ), and these differences are statistically significant $(\mathrm{p}<0.01)$. Also, the mean knowledge score of all criteria for effective breastfeeding was higher for the control group than the intervention group in the seven month follow-up visit $(23 \%$ versus $18 \%, p<0.05)$ and the 13 month follow-up interview $(28 \%$ versus $21 \%, \mathrm{p}<0.01)$. Reasons for these findings should be explored.

The findings of Phase I of this study showed that the IUD, the injectable and the pill were the most frequently used methods by women in the two study groups. Table 11 shows data on the mean percent general knowledge score for women in both study groups currently using these methods. The mean percent general knowledge score for women using the IUD was higher for the intervention group than the control group in both follow-up visits, $(25.9 \%$ versus $23 \%$ for the first visit and $29.9 \%$ versus $26.1 \%$, respectively, for the second visit). These differences were statistically significant $(\mathrm{p}<0.01)$.

Table 11: Mean percent general knowledge score ${ }^{a}$ of method currently used for women at seven month and 13 month follow-up interviews

\begin{tabular}{|l|c|c|c|c|}
\hline \multirow{2}{*}{ IUD } & \multicolumn{2}{|c|}{ Seven month interview } & \multicolumn{2}{c|}{ 13 month interview } \\
\cline { 2 - 5 } & Intervention & Control & Intervention & Control \\
\hline Injectables & $25.9^{* *}$ & 23.0 & $29.9^{* *}$ & 26.1 \\
& $\mathrm{~N}=163$ & $\mathrm{~N}=168$ & $\mathrm{~N}=145$ & $\mathrm{~N}=161$ \\
\hline Pills & 20.7 & 22.2 & 26.1 & 25.1 \\
& $\mathrm{~N}=58$ & $\mathrm{~N}=81$ & $\mathrm{~N}=56$ & $\mathrm{~N}=65$ \\
\hline & 20.0 & 18.7 & 23.4 & 22.0 \\
& $\mathrm{~N}=39$ & $\mathrm{~N}=15$ & $\mathrm{~N}=34$ & $\mathrm{~N}=24$ \\
\hline
\end{tabular}

${ }^{* *} \mathrm{p}<0.01$

${ }^{a}$ See description of Index 3 in Appendix I.

To examine the sustainability of the impact of the intervention, women who reported using the same method continuously at the seven and 13 month follow-up home interviews were screened, and the mean percent general knowledge score was calculated for those women (Table 12). The data reflect the same patterns as shown in Table 11, but the differences between values of the scores were greater. 
Table 12: Mean percent general knowledge score ${ }^{a}$ by method among women ${ }^{b}$ who received the specified methods at the index visit and continued using same method at seven month and 13 month interviews

\begin{tabular}{|l|c|c|c|c|}
\hline \multirow{2}{*}{} & \multicolumn{2}{|c|}{ Seven month interview } & \multicolumn{2}{c|}{ 13 month interview } \\
\cline { 2 - 5 } & Intervention & Control & Intervention & Control \\
\hline IUD & $51.3^{* *}$ & 46.2 & $59.9^{* *}$ & 52.5 \\
& $\mathrm{~N}=153$ & $\mathrm{~N}=157$ & $\mathrm{~N}=136$ & $\mathrm{~N}=140$ \\
\hline Injectables & 42.1 & 43.9 & 52.7 & 49.9 \\
& $\mathrm{~N}=49$ & $\mathrm{~N}=69$ & $\mathrm{~N}=44$ & $\mathrm{~N}=51$ \\
\hline \multirow{2}{*}{ Pill } & $44.1^{* *}$ & 34.5 & 45.3 & 44.7 \\
& $\mathrm{~N}=25$ & $\mathrm{~N}=7$ & $\mathrm{~N}=13$ & $\mathrm{~N}=8$ \\
\hline
\end{tabular}

${ }^{* *} p<0.01$

${ }^{\text {a }}$ See description of Index 3 in Appendix I.

${ }^{b}$ These numbers do not include current users of these methods who switched to them after the index visit.

These data suggest that women who switched methods (shown in Table 11) perhaps had not received sufficient information on their method either because they changed methods without consultation with clinic staff, or consulted with clinic staff but did not receive enough information on the method received at the index visit.

Knowledge about warning signs of the IUD, injectables and pills for the two study groups is shown in Table 13 (maximum score $=100$ ). The data indicate a higher mean percent knowledge score among women in the intervention group compared with the control group, with the exception of IUD users at the 13 month follow-up interview, though the differences were not significant. The most notable increase in the score was for the pill at the seven month follow-up visit, where the average score for the intervention group was 44 percent versus 35 percent for the intervention group (difference is statistically significant, $\mathrm{p}<0.01$ ).

Table 13: Mean percent knowledge score ${ }^{a}$ of warning signs for women currently using the specified methods at seven month and 13 month follow-up

\begin{tabular}{|l|c|c|c|c|}
\hline \multirow{2}{*}{ IUD } & \multicolumn{2}{|c|}{ Seven month interview } & \multicolumn{2}{c|}{ 13 month interview } \\
\cline { 2 - 5 } & Intervention & Control & Intervention & Control \\
\hline Injectables & 44.9 & 44.5 & 46.7 & 48.4 \\
& $\mathrm{~N}=163$ & $\mathrm{~N}=168$ & $\mathrm{~N}=145$ & $\mathrm{~N}=161$ \\
\hline Pills & 42.2 & 41.7 & 46.4 & 43.1 \\
& $\mathrm{~N}=58$ & $\mathrm{~N}=81$ & $\mathrm{~N}=56$ & $\mathrm{~N}=65$ \\
\hline & $44.1^{* *}$ & 34.5 & 45.3 & 44.7 \\
& $\mathrm{~N}=39$ & $\mathrm{~N}=15$ & $\mathrm{~N}=34$ & $\mathrm{~N}=24$ \\
\hline
\end{tabular}

${ }^{* *} p<0.01$

${ }^{\mathrm{a}}$ See description of Index 4 in Appendix I. 


\section{Correct use of family planning method}

Women in both study groups were asked questions about the correct use of the method they were currently using. Based on women's responses, mean percent scores of knowledge of correct use of the three commonly used methods (the IUD, pills and injectables) were calculated (maximum score $=100)$. The results are shown in Table 14 .

Table 14: Mean percent score ${ }^{a}$ of knowledge of correct use for women currently using the specified methods at seven month and 13 month follow-up interviews

\begin{tabular}{|l|c|c|c|c|}
\hline \multirow{2}{*}{} & \multicolumn{2}{|c|}{ Seven month interview } & \multicolumn{2}{c|}{ 13 month interview } \\
\cline { 2 - 5 } & Intervention & Control & Intervention & Control \\
\hline Pills & 36.2 & 36.2 & 38.6 & 37.3 \\
& $\mathrm{~N}=39$ & $\mathrm{~N}=15$ & $\mathrm{~N}=34$ & $\mathrm{~N}=24$ \\
\hline IUD & $41.4^{* *}$ & 36.9 & $45.1^{* *}$ & 39.8 \\
& $\mathrm{~N}=163$ & $\mathrm{~N}=168$ & $\mathrm{~N}=145$ & $\mathrm{~N}=161$ \\
\hline Injectables & $30.6^{* *}$ & 34.6 & 34.8 & 34.6 \\
& $\mathrm{~N}=58$ & $\mathrm{~N}=81$ & $\mathrm{~N}=56$ & $\mathrm{~N}=65$ \\
\hline
\end{tabular}

${ }^{* *} \mathrm{p}<0.01$

${ }^{a}$ See description of Index 5 in Appendix I.

The scores reflect rather low levels of knowledge of correct use of methods in both study groups; only about one-third of women gave correct answers on correct method use. Also, there was little or no improvement in this score in the intervention group compared with the control group. The only exception was the IUD users, where women in the intervention group were more likely to give correct answers compared with women in the control group (the score was $41 \%$ versus $37 \%$ for the seven month interview, and $45 \%$ versus $40 \%$ for the 13 month interview, respectively, both differences are significant, $p<0.01$ ). For injectable users, knowledge of women in the control group was better than those in the intervention group at seven months.

\section{Prompt Switching}

According to the definitions of variables in the study, a woman is considered to be a prompt switcher if: there is no method-free interval between two contraceptive methods; she did not have sex during that method-free interval; or if she used rhythm or withdrawal during the method-free period. The first definition was applied for analysis in this section.

Table 15 presents data on women who changed from the method they received at the index visit to another method. The data, thus, indicate first switch between the time of index visit and the time of the 13 month follow-up home visit. Slightly more than one-quarter of the women in both study groups changed methods at least once. The majority of women switched to a second method quickly. About 76 percent of the intervention group and 73 percent of the control group switched to another method within a month of discontinuing the first method. 


\section{Table 15: Percentage distribution of switchers ${ }^{a}$ between the index visit and the 13 month follow-up interview, by method-free interval and mean period of non-use}

\begin{tabular}{|c|c|c|}
\hline \multirow{2}{*}{$\begin{array}{l}\text { Method-free } \\
\text { interval (in } \\
\text { months) }\end{array}$} & $\begin{array}{c}|c| \\
\text { Intervention } \\
\mathbf{N = 8 2}\end{array}$ & $\begin{array}{c}\text { Control } \\
\mathbf{N}=\mathbf{8 1}\end{array}$ \\
\cline { 2 - 3 } & 75.6 & 72.8 \\
\hline 0 & 7.3 & 9.9 \\
\hline 1 & 1.2 & 4.9 \\
\hline 2 & 4.8 & 3.7 \\
\hline 3 & 1.2 & 2.4 \\
\hline 4 & 1.2 & 1.2 \\
\hline 5 & 2.4 & 1.2 \\
\hline 6 & - & 1.2 \\
\hline 7 & 2.4 & 1.2 \\
\hline 8 & 2.4 & 1.2 \\
\hline 9 & 1.2 & 1.2 \\
\hline 10 & - & 1.2 \\
\hline 11 & $1.03^{* *}$ & 0.90 \\
\hline $\begin{array}{l}\text { Mean } \\
\text { method-free } \\
\text { interval }\end{array}$ & & \\
\hline S.D. & 2.38 & 2.13 \\
\hline
\end{tabular}

${ }^{* *} \mathrm{p}<0.01$

a Includes only women who switched to another method (first change) and did not become pregnant during the method-free interval (both currently using a method and not currently using at 13 month follow-up).

The data include only first time switchers who did not become pregnant during the method-free interval. Also, none of the switchers used any traditional method during the method-free interval (data not shown). Among all switchers who changed methods for the first time during this period, very few changed a second time (eight women from the intervention group and 13 women from the control group). Again, the second method change was mostly done after a short method-free interval (less than one month, data not shown).

Table 16 presents additional insights on method switchers. The table shows the distribution of women who ever switched to another method during the period between the index visit and the 13 month follow-up interview by method used at both the index visit and the 13 month follow-up interview. Note that the table excludes those women who were using same method at both the index visit and the 13 month follow-up home visit and those who changed methods in the interim. 
Table 16: Distribution of clients at the 13 month follow-up interview who ever switched to another method since the index visit, by type of method received at the index visit and method currently used

\begin{tabular}{|c|c|c|c|c|c|c|c|}
\hline \multirow{3}{*}{$\begin{array}{l}\text { Method currently } \\
\text { used at the } 13 \text { month } \\
\text { follow-up interview }\end{array}$} & \multicolumn{7}{|c|}{ Method received at the index visit } \\
\hline & \multicolumn{7}{|c|}{ Intervention Group } \\
\hline & Pills & IUD & Injectable & Norplant & Condom & Other & Total \\
\hline Pills & 16 & 12 & 9 & - & - & - & 37 \\
\hline IUD & 5 & 136 & 4 & - & - & - & 145 \\
\hline Injectable & 3 & 9 & 44 & - & - & - & 56 \\
\hline Norplant & 1 & - & - & 1 & - & - & 2 \\
\hline Condom & - & - & - & - & 2 & - & 2 \\
\hline Other & 2 & 2 & - & - & - & - & 4 \\
\hline \multirow[t]{3}{*}{ Number of women } & 27 & 159 & 57 & 1 & 2 & - & 246 \\
\hline & \multicolumn{7}{|c|}{ Control Group } \\
\hline & Pills & IUD & Injectable & Norplant & Condom & Other & Total \\
\hline Pills & 8 & 7 & 9 & 1 & 1 & - & 26 \\
\hline IUD & 3 & 140 & 18 & - & - & - & 161 \\
\hline Injectable & 2 & 12 & 51 & - & - & - & 65 \\
\hline Norplant & - & 1 & - & - & - & - & 1 \\
\hline Condom & - & - & - & - & - & - & - \\
\hline Other & - & - & 1 & - & - & - & 1 \\
\hline Number of women & 13 & 160 & 79 & 1 & 1 & - & 254 \\
\hline
\end{tabular}

\section{Client satisfaction with the method received at the index visit}

At both follow-up visits women were asked a number of questions to determine their satisfaction with the method received at their index visit. These questions included perceived method effectiveness, husband's approval about method use, perceived convenience of use, affordability of method, and general satisfaction with method use. Table 17 shows that the vast majority of women were satisfied with most of aspects of the method selected. Very few women reported satisfaction on fewer than five items in either the intervention or the control group.

Table 17: Percent of women reporting of satisfaction with method received at index visit: satisfaction score ${ }^{a}$

\begin{tabular}{|c|c|c|c|c|}
\hline \multirow[b]{2}{*}{$\begin{array}{l}\text { Percent of women who } \\
\text { were satisfied with: }\end{array}$} & \multicolumn{2}{|c|}{ Seven month interview } & \multicolumn{2}{|c|}{13 month interview } \\
\hline & $\begin{array}{c}\text { Intervention } \\
\mathbf{N}=300\end{array}$ & $\begin{array}{c}\text { Control } \\
\mathrm{N}=300\end{array}$ & $\begin{array}{c}\text { Intervention } \\
\mathrm{N}=295\end{array}$ & $\begin{array}{l}\text { Control } \\
\mathrm{N}=295\end{array}$ \\
\hline $1-2$ items & 4.0 & 0.0 & 2.8 & 0.0 \\
\hline 3-4 items & 4.0 & 6.0 & 5.1 & 2.4 \\
\hline $5-6$ items & 12.3 & 13.4 & 13.2 & 18.3 \\
\hline Satisfied with all 7 items & $79.7^{* *}$ & 80.7 & $79.0^{* *}$ & 79.3 \\
\hline
\end{tabular}

${ }^{* *} p<0.01$

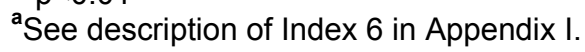

Additional insights into satisfaction with the method received at the index visit are presented in Table 18. A list of all possible side effects of each family planning method was included in the study instrument. Women were asked about their knowledge of side effects, if they had experienced them, and if yes, if they were able to tolerate them or not. Only data for the three 
most used methods (i.e., pill, IUD, and injectables) are shown. A total score was computed for each client, with a possible score ranging between zero and six for the pill and zero and four for both the IUD and the injectables. The scores were then computed relative to 100 .

Table 18 reflects the low level of knowledge about method side effects in both study groups. Data for pills is not presented because the number of cases in the control group is less than 20, hence no tests of significance could be run. Women in the intervention group who used the IUD were more likely to report experiencing method side effects at the 13 month follow-up interview, compared with the women in the control group. Also, women in the intervention group who used the IUD or injectables were more likely to report that they were able to tolerate method side effects compared with women in the control group. Differences noted in this regard were statistically significant $(\mathrm{p}<0.01)$.

Table 18: Percent of women reporting method side effects at seven month and 13 month follow-up interviews

\begin{tabular}{|c|c|c|c|c|c|}
\hline \multirow{2}{*}{$\begin{array}{l}\text { Most } \\
\text { frequently } \\
\text { used } \\
\text { method }\end{array}$} & \multirow[t]{2}{*}{$\begin{array}{l}\text { Knowledge and } \\
\text { management of } \\
\text { side effects }\end{array}$} & \multicolumn{2}{|c|}{ Intervention } & \multicolumn{2}{|c|}{ Control } \\
\hline & & $\begin{array}{c}\text { Seven } \\
\text { month } \\
\text { interview }\end{array}$ & $\begin{array}{l}13 \text { month } \\
\text { interview }\end{array}$ & $\begin{array}{c}\text { Seven } \\
\text { month } \\
\text { interview }\end{array}$ & $\begin{array}{l}13 \text { month } \\
\text { interview }\end{array}$ \\
\hline \multirow[t]{4}{*}{ IUD } & $\begin{array}{l}\text { Know of } \\
\text { method side } \\
\text { effects }\end{array}$ & $\begin{array}{c}37.6 \\
N=180\end{array}$ & $\begin{array}{c}42.2 \\
N=181\end{array}$ & $\begin{array}{c}36.6 \\
N=185\end{array}$ & $\begin{array}{c}40.5 \\
N=184\end{array}$ \\
\hline & $\begin{array}{c}\text { Have } \\
\text { experienced } \\
\text { side effects }\end{array}$ & $\begin{array}{c}35.5 \\
N=148\end{array}$ & $\begin{array}{l}39.1^{* *} \\
N=148\end{array}$ & $\begin{array}{c}32.7 \\
N=120\end{array}$ & $\begin{array}{c}34.8 \\
N=124\end{array}$ \\
\hline & $\begin{array}{l}\text { Can tolerate } \\
\text { side effects }\end{array}$ & $\begin{array}{c}25.7 \\
N=148\end{array}$ & $\begin{array}{l}28.5^{\star *} \\
N=148\end{array}$ & $\begin{array}{c}22.8 \\
N=120\end{array}$ & $\begin{array}{c}25.5 \\
N=124\end{array}$ \\
\hline & $\begin{array}{l}\text { Cannot } \\
\text { tolerate side } \\
\text { effects }\end{array}$ & $\begin{array}{c}10.1 \\
N=148\end{array}$ & $\begin{array}{c}9.2 \\
N=148\end{array}$ & $\begin{array}{c}10.8 \\
N=120\end{array}$ & $\begin{array}{c}7.2 \\
N=124\end{array}$ \\
\hline \multirow[t]{4}{*}{ Injectables } & $\begin{array}{l}\text { Know of } \\
\text { method side } \\
\text { effects }\end{array}$ & $\begin{array}{l}31.0 \\
N=71\end{array}$ & $\begin{array}{c}39.7 \\
N=71\end{array}$ & $\begin{array}{c}34.9 \\
N=95\end{array}$ & $\begin{array}{c}40.0 \\
N=96\end{array}$ \\
\hline & $\begin{array}{c}\text { Have } \\
\text { experienced } \\
\text { side effects }\end{array}$ & $\begin{array}{c}30.5 \\
N=61\end{array}$ & $\begin{array}{l}35.5 \\
N=58\end{array}$ & $\begin{array}{c}29.6 \\
N=73\end{array}$ & $\begin{array}{c}30.3 \\
N=68\end{array}$ \\
\hline & $\begin{array}{l}\text { Can tolerate } \\
\text { side effects }\end{array}$ & $\begin{array}{c}19.3 \\
N=61\end{array}$ & $\begin{array}{l}23.8^{* *} \\
\mathrm{~N}=58\end{array}$ & $\begin{array}{c}18.1 \\
N=73\end{array}$ & $\begin{array}{c}12.6 \\
N=68\end{array}$ \\
\hline & $\begin{array}{l}\text { Cannot } \\
\text { tolerate side } \\
\text { effects }\end{array}$ & $\begin{array}{l}11.5 \\
N=61\end{array}$ & $\begin{array}{c}11.0 \\
N=58\end{array}$ & $\begin{array}{c}10.7 \\
N=73\end{array}$ & $\begin{array}{c}16.8 \\
N=68\end{array}$ \\
\hline
\end{tabular}

${ }^{* *} \mathrm{p}<0.01$

See description of Index 7 in Appendix I. 


\section{Client satisfaction with services at the clinic}

Women were asked about their satisfaction with aspects of clinic preparedness for providing family planning services. There were five items, including availability and condition of the waiting area, privacy during the consultation session and medical examination, the availability of a toilet, and its convenience for use. Table 19 shows that women in the intervention group reported more satisfaction with clinic preparedness than women in the control group at both the follow-up visits, and the differences were statistically significant.

Table 19: Percent of women reporting satisfaction with clinic's physical preparedness for providing family planning services: satisfaction score ${ }^{a}$

\begin{tabular}{|l|c|c|c|c|}
\hline \multirow{2}{*}{$\begin{array}{l}\text { Percent of women who } \\
\text { were satisfied with: }\end{array}$} & \multicolumn{2}{|c|}{ Seven month interview } & \multicolumn{2}{c|}{$\mathbf{1 3}$ month interview } \\
\cline { 2 - 5 } & $\begin{array}{c}\text { Intervention } \\
\mathbf{N = 3 0 0}\end{array}$ & $\begin{array}{c}\text { Control } \\
\mathbf{N = 3 0 0}\end{array}$ & $\begin{array}{c}\text { Intervention } \\
\mathbf{N = 2 9 5}\end{array}$ & $\begin{array}{c}\text { Control } \\
\mathbf{N = 2 9 5}\end{array}$ \\
\hline 1-2 items & 1.6 & 15.0 & 1.0 & 17.3 \\
\hline 3-4 items & 22.8 & 50.6 & 11.6 & 50.8 \\
\hline All 5 items & $75.7^{* *}$ & 31.0 & $87.5^{* *}$ & 31.9 \\
\hline
\end{tabular}

${ }^{* *} \mathrm{p}<0.01$

${ }^{\text {a }}$ See description of Index 8 in Appendix I

Additional aspects of women's satisfaction with clinic services received at the index visit are shown in Table 20. These aspects broadly cover satisfaction with providers' counseling skills and providers' technical competence.

Table 20: Percent of women reporting satisfaction with services provided in the clinic at the index visit

\begin{tabular}{|l|c|c|c|c|}
\hline & \multicolumn{2}{|c|}{$\begin{array}{c}\text { Seven month } \\
\text { interview }\end{array}$} & \multicolumn{2}{c|}{$\mathbf{1 3}$ month interview } \\
\cline { 2 - 4 } & $\begin{array}{c}\text { Intervention } \\
\mathbf{N}=\mathbf{3 0 0}\end{array}$ & $\begin{array}{c}\text { Control } \\
\mathbf{N = 3 0 0}\end{array}$ & $\begin{array}{c}\text { Intervention } \\
\mathbf{N = 2 9 5}\end{array}$ & $\begin{array}{c}\text { Control } \\
\mathbf{N}=\mathbf{2 9 5}\end{array}$ \\
\hline $\begin{array}{l}\text { Provider gave client excellent chance to tell her } \\
\text { needs }\end{array}$ & $58.0^{* *}$ & 20.3 & $42.7^{* *}$ & 15.3 \\
\hline $\begin{array}{l}\text { Provider explained all the family planning } \\
\text { methods available at clinic }\end{array}$ & $86.7^{* *}$ & 74.0 & $82.0^{* *}$ & 67.5 \\
\hline Doctor performed breast exam & $60.3^{* *}$ & 39.7 & $69.2^{* *}$ & 41.4 \\
\hline Doctor performed pelvic exam & $74.7^{*}$ & 66.7 & $79.0^{* *}$ & 64.1 \\
\hline $\begin{array}{l}\text { Doctor asked for detailed examination before } \\
\text { giving the method }\end{array}$ & 2.7 & 1.3 & $4.4^{* *}$ & 1.0 \\
\hline $\begin{array}{l}\text { Doctor gave an idea about the unsafe method for } \\
\text { client }\end{array}$ & $47.3^{* *}$ & 15.0 & $39.0^{* *}$ & 9.8 \\
\hline Both client and doctor chose the used method & $26.3^{* *}$ & 10.7 & $24.7^{* *}$ & 16.6 \\
\hline $\begin{array}{l}\text { Doctor informed client that she can chose the } \\
\text { method she wants }\end{array}$ & $91.0^{* *}$ & 81.3 & 92.5 & 89.5 \\
\hline $\begin{array}{l}\text { Doctor informed client that she can change the } \\
\text { method if she feels unsatisfied }\end{array}$ & $95.3^{* *}$ & 82.0 & $96.9^{* *}$ & 87.1 \\
\hline $\begin{array}{l}\text { Doctor talked about the advantages and } \\
\text { disadvantages of the method }\end{array}$ & $79.3^{* *}$ & 42.0 & $70.8^{* *}$ & 46.8 \\
\hline Doctor talked about method side effects in detail & 42.3 & 15.7 & $39.7^{* *}$ & 9.2 \\
\hline $\begin{array}{l}\text { Doctor gave a good idea about the correct use of } \\
\text { the method in detail }\end{array}$ & 63.7 & 30.0 & $61.0^{* *}$ & 19.0 \\
\hline Doctor told her to come back for follow-up & $92.7^{* *}$ & 85.0 & 88.4 & 88.5 \\
\hline Doctor discussed how to protect her from STls & $25.3^{* *}$ & 11.3 & $27.8^{* *}$ & 9.5 \\
\hline Client treated with respect & 99.3 & 99.0 & $99.3^{*}$ & 97.3 \\
\hline Provider was concerned about the client's health & 97.7 & 96.7 & $98.6^{* *}$ & 90.2 \\
\hline Client will recommend the clinic to friends & 97.0 & 97.0 & 95.9 & 93.2 \\
\hline
\end{tabular}


The data reflect substantial improvement in almost all aspects of clinic services received among the intervention group. Also, differences are significant in most aspects. Aspects of services received were grouped in 13 items, and a satisfaction score based on them is shown in Table 21 (see description of Index 9 in Appendix I).

The data show that a substantially larger percentage of women in the intervention group are satisfied with ten or more items examined, compared with women in the control group. The mean satisfaction score for services at the seven month follow-up visit for women in the intervention and control group were 72 percent and 55 percent, respectively $(\mathrm{p}<0.01)$. Likewise, the mean satisfaction scores at the 13 month home visit were 81 percent in the intervention group compared with 60 percent in the control group $(\mathrm{p}<0.01)$.

Table 21: Percent of women reporting satisfaction with services provided at the clinic at the index visit: satisfaction score ${ }^{a}$

\begin{tabular}{|c|c|c|c|c|}
\hline \multirow[b]{2}{*}{$\begin{array}{l}\text { Percent of women } \\
\text { satisfied with: }\end{array}$} & \multicolumn{2}{|c|}{ Seven month interview } & \multicolumn{2}{|c|}{13 month interview } \\
\hline & $\begin{array}{l}\text { Intervention } \\
\quad N=300\end{array}$ & $\begin{array}{c}\text { Control } \\
\mathrm{N}=300\end{array}$ & $\begin{array}{l}\text { Intervention } \\
\quad \mathrm{N}=295\end{array}$ & $\begin{array}{c}\text { Control } \\
\mathrm{N}=295\end{array}$ \\
\hline $1-3$ items & 2.6 & 10.4 & 0.3 & 7.1 \\
\hline $4-6$ items & 9.3 & 26.9 & 8.1 & 21.0 \\
\hline $7-9$ items & 35.3 & 41.4 & 23.4 & 44.0 \\
\hline $10-13$ items & 51.4 & 20.0 & 58.9 & 27.1 \\
\hline Mean satisfaction score & $72.4^{* *}$ & 55.1 & $80.7^{* \star}$ & 60.6 \\
\hline
\end{tabular}

${ }^{* *} \mathrm{p}<0.01$

a See description of Index 9 in Appendix l.

Note: Aspects of quality of care provided in Table 20 were combined in 13 items to estimate the satisfaction score in this table.

\section{Ability to achieve reproductive intentions}

According to the case definition of the study participants, women in this panel study did not want to have any more children, at least in the following 12-month period. Some women, however, may change their reproductive intentions, while some others may become pregnant during periods of method use or non-use. The latter category of women, thus, would not be able to achieve their reproductive intentions.

Table 22 shows data on contraceptive use dynamics for the two study groups. Since enrollment in the panel study (seven months after the index visit), about 90 percent of the intervention and the control groups were still using contraceptive methods. About one-tenth of each group, however, was not using any contraceptive method, but the majority of them were not pregnant. Only 11 women in the intervention group (4\%) and 4 women in the control group (1\%) were pregnant at the time of the seven month follow-up home interview. Six months later, slightly fewer women were still using family planning methods in both the intervention and the control groups $(83 \%$ and $86 \%$, respectively). Fifteen women (5\%) from the intervention group and 11 women (4\%) from the control group reported being pregnant at the 13 month follow-up home interview. None of the above differences between the two study groups were statistically significant.

Table 22 also indicates that, overall, about two-thirds of women in the two study groups who were no longer using a method reported reduced need for the method, and the other third reported quality related issues for non-use. About one-third of women in the study groups reported changing their 
reproductive intentions at both the seven month and the 13 month follow-up home interviews. They wanted to become pregnant, and they discontinued method use (it is not known, however, which one happened first). Almost all of those women were able to become pregnant (data not shown).

In addition, between one-tenth and one-fourth of women in both study groups who discontinued use did so for reasons other than changing reproductive intentions. Most of those reasons (10-14\% of all cases) were related to the lack of exposure (i.e., infrequent sex, husband away, and marital dissolution). Other noticeable cases were related to menopause or women's belief that they would not get pregnant.

Table 22: Contraceptive use dynamics at seven and 13 month home interviews

\begin{tabular}{|l|c|c|c|c|}
\hline \multirow{2}{*}{ Status of contraceptive use (\%) } & \multicolumn{2}{|c|}{ Seven month interview } & \multicolumn{2}{c|}{$\mathbf{1 3}$ month interview } \\
\cline { 2 - 5 } & $\begin{array}{c}\text { Intervention } \\
\mathbf{N = 3 0 0}\end{array}$ & $\begin{array}{c}\text { Control } \\
\mathbf{N = 3 0 0}\end{array}$ & $\begin{array}{c}\text { Intervention } \\
\mathbf{N = 2 9 5}\end{array}$ & $\begin{array}{c}\text { Control } \\
\mathbf{N = 2 9 5}\end{array}$ \\
\hline Current users: & 89.7 & 91.3 & 83.4 & 86.1 \\
- same method & 77.7 & 78.3 & 67.5 & 67.5 \\
- other method/switchers & 12.0 & 13.0 & 15.9 & 18.6 \\
& $(\mathrm{~N}=269)$ & $(\mathrm{N}=274)$ & $(\mathrm{N}=246)$ & $(\mathrm{N}=254)$ \\
\hline Current non users: & 10.3 & 8.7 & 16.6 & 13.9 \\
- not pregnant & 6.6 & 7.4 & 11.5 & 10.2 \\
- pregnant & 3.7 & 1.3 & 5.1 & 3.7 \\
& $(\mathrm{~N}=31)$ & $(\mathrm{N}=26)$ & $(\mathrm{N}=49)$ & $(\mathrm{N}=41)$ \\
\hline Reasons of discontinuation (\%) & Intervention & Control & Intervention & Control \\
& $\mathrm{N}=31$ & $\mathrm{~N}=26$ & $\mathrm{~N}=49$ & $\mathrm{~N}=41$ \\
\hline Reduced need: & 61.3 & 65.4 & 59.2 & 58.5 \\
- want to become pregnant & 35.4 & 38.7 & 36.8 & 46.3 \\
- infrequent sex/husband away & 12.9 & 11.5 & 14.3 & 9.8 \\
- menopause/unable to get pregnant & 6.5 & 3.8 & 2.0 & 2.4 \\
- marital dissolution & - & 7.6 & 4.0 & - \\
- others & 6.5 & 3.8 & 2.1 & - \\
\hline Quality related reasons: & 38.7 & 34.6 & 40.8 & 41.5 \\
- became pregnant & 3.2 & 3.8 & 2.0 & 2.4 \\
- husband disapproved & 3.2 & - & 4.0 & - \\
- side effects & 22.6 & 23.2 & 20.5 & 26.9 \\
- health concerns & 6.5 & 7.6 & 14.3 & 12.2 \\
- cost too much & 3.2 & - & - & - \\
\hline
\end{tabular}

Discontinuation of method use due to low level of quality of care constituted between one-third to two-fifths of all method discontinuation cases for both study groups at both home follow-up visits, and observed differences were not statistically significant between the intervention and the control group. Suffering from method side effects or having some health concerns related to the method use represented the majority of these numerically small cases. Only four women were exposed to unplanned pregnancy (one in each study group in each of the two home visits). However, some of the other women who discontinued method use due to quality related reasons may have been exposed to the risk of having unplanned pregnancies. Few cases of discontinuation were due to husband's disapproval or the high cost of method.

\section{Continued use of family planning methods}

Life table cumulative continuation rates for the IUD and the pill were estimated following the method described earlier in the data entry and analysis section. Tables 23 through Table 25 and Figures 2-4 show related study findings. 
Table 23: Cumulative continuation rates for all methods for the intervention and control groups ${ }^{a}$

\begin{tabular}{|c|c|c|}
\hline $\begin{array}{c}\text { Ordinal } \\
\text { months }\end{array}$ & $\begin{array}{c}\text { Intervention } \\
\text { Group } \\
\mathbf{N = 3 0 0}\end{array}$ & $\begin{array}{c}\text { Control Group } \\
\mathbf{N = 3 0 0}\end{array}$ \\
\hline 0 & 99.2 & 99.2 \\
\hline 1 & 97.4 & 96.0 \\
\hline 2 & 96.5 & 94.3 \\
\hline 3 & 90.5 & 91.0 \\
\hline 4 & 88.6 & 89.4 \\
\hline 5 & 87.3 & 88.1 \\
\hline 6 & 84.4 & 85.3 \\
\hline 7 & 81.4 & 84.4 \\
\hline 8 & 78.5 & 82.7 \\
\hline 9 & 75.8 & 79.5 \\
\hline 10 & 73.1 & 76.5 \\
\hline 11 & 70.0 & 73.4 \\
\hline 12 & 67.6 & 71.0 \\
\hline 13 & 66.0 & 68.1 \\
\hline
\end{tabular}

${ }^{\mathrm{a}}$ Differences are not significant

No significant differences were observed in the cumulative continuation rates for all methods. By the end of the 13 month period, cumulative continuation rates were 68 percent among the control group, compared with 66 percent for the intervention group (not significant, see Table 23 and Figure 2). These findings are in agreement with the Egypt 2000 DHS findings that indicated that 3 in 10 users in Egypt stop using a method within 12 months of starting use (El Zanaty and Way 2001).

Figure 2: Cumulative continuation rates by month for intervention and control groups (all methods)

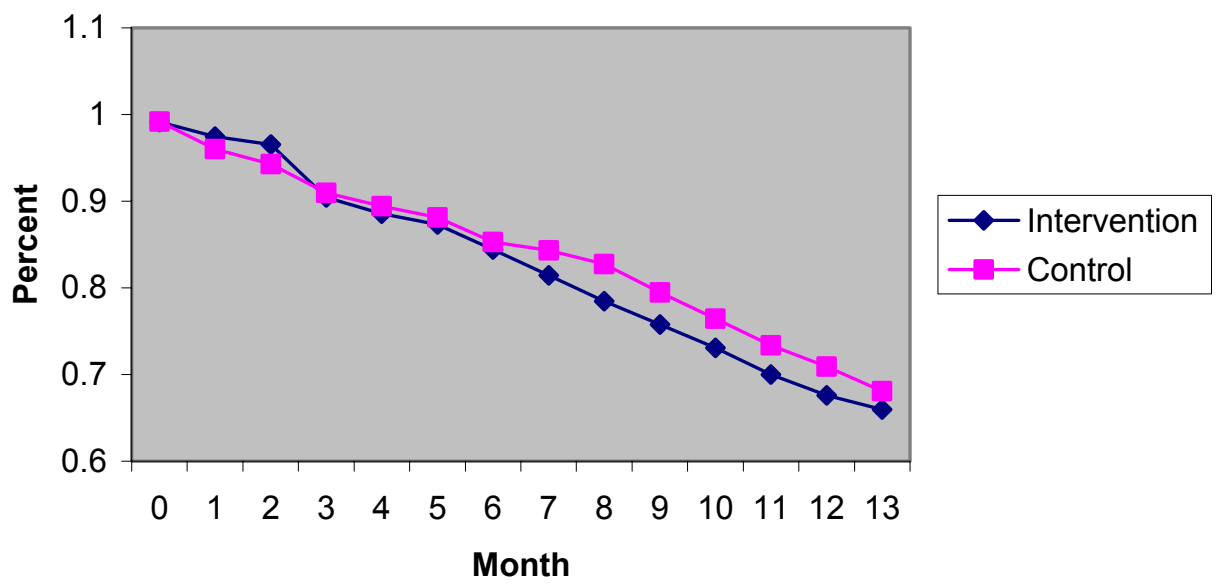


Life table cumulative continuation rates were also calculated for the IUD and the pill. As mentioned earlier, the majority of women in the two study groups were using the IUD. Table 24 and Figure 3 show that the differences in the continuation rates for the IUD between the two groups were very small and insignificant. Overall, the continuation rates for the IUD after 12 months of use were about 80 percent for both study groups, relatively lower than similar rates reported by the Egypt 2000 DHS at 86 percent (El Zanaty and Way 2001).

Table 24: Cumulative continuation rates for the IUD for the intervention and control groups ${ }^{a}$

\begin{tabular}{|c|c|c|}
\hline Ordinal months & $\begin{array}{c}\text { Intervention Group } \\
\mathbf{N = 3 0 0}\end{array}$ & $\begin{array}{c}\text { Control Group } \\
\mathbf{N = 3 0 0}\end{array}$ \\
\hline 0 & 98.9 & 98.5 \\
\hline 1 & 98.4 & 96.5 \\
\hline 2 & 97.9 & 95.5 \\
\hline 3 & 95.7 & 94.5 \\
\hline 4 & 95.1 & 93.4 \\
\hline 5 & 94.5 & 91.8 \\
\hline 6 & 92.9 & 90.2 \\
\hline 7 & 90.6 & 89.7 \\
\hline 8 & 88.9 & 88.6 \\
\hline 9 & 86.0 & 87.5 \\
\hline 10 & 84.9 & 85.3 \\
\hline 11 & 82.6 & 83.0 \\
\hline 12 & 79.7 & 80.7 \\
\hline 13 & 77.7 & 78.8 \\
\hline
\end{tabular}

${ }^{\mathrm{a} D i f f e r e n c e s}$ are not significant

Figure 3: Cumulative continuation rates by month for intervention and control groups (IUD)

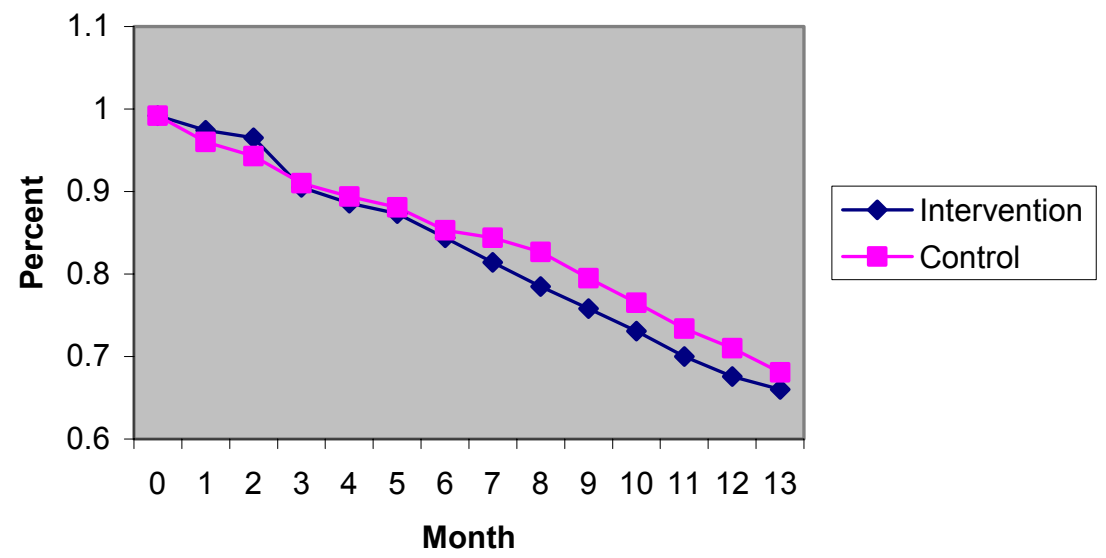

Lastly, Table 25 and Figure 4 show similar data on cumulative continuation rates of the pill. Despite relatively larger differences in continuation rates between the two study groups, they 
were insignificant. It is worth noting that, unlike the case for 12-month continuation rates for all methods and for the IUD, continuation rates for the pill indicated by the Egypt 2000 DHS were higher $(52 \%)$ than corresponding rates reflected by the present study findings ( $38 \%$ for the intervention group and $43 \%$ for the control group). Reasons for this gap should be investigated.

Table 25: Cumulative continuation rates for the pill for intervention and control groups ${ }^{a}$

\begin{tabular}{|c|c|c|}
\hline Ordinal months & $\begin{array}{c}\text { Intervention Group } \\
\mathbf{N = 3 0 0}\end{array}$ & $\begin{array}{c}\text { Control Group } \\
\mathbf{N = 3 0 0}\end{array}$ \\
\hline 0 & 98.6 & 100.0 \\
\hline 1 & 92.8 & 86.2 \\
\hline 2 & 89.9 & 78.8 \\
\hline 3 & 85.0 & 65.2 \\
\hline 4 & 78.0 & 62.2 \\
\hline 5 & 74.2 & 62.2 \\
\hline 6 & 70.3 & 62.2 \\
\hline 7 & 66.4 & 58.6 \\
\hline 8 & 58.5 & 55.0 \\
\hline 9 & 54.3 & 47.4 \\
\hline 10 & 45.0 & 43.3 \\
\hline 11 & 40.2 & 43.3 \\
\hline 12 & 37.6 & 43.3 \\
\hline 13 & 34.5 & 43.3 \\
\hline
\end{tabular}

${ }^{\mathrm{a}}$ Differences are not significant

Figure 4: Cumulative continuation rates by month for intervention and control groups (pill)

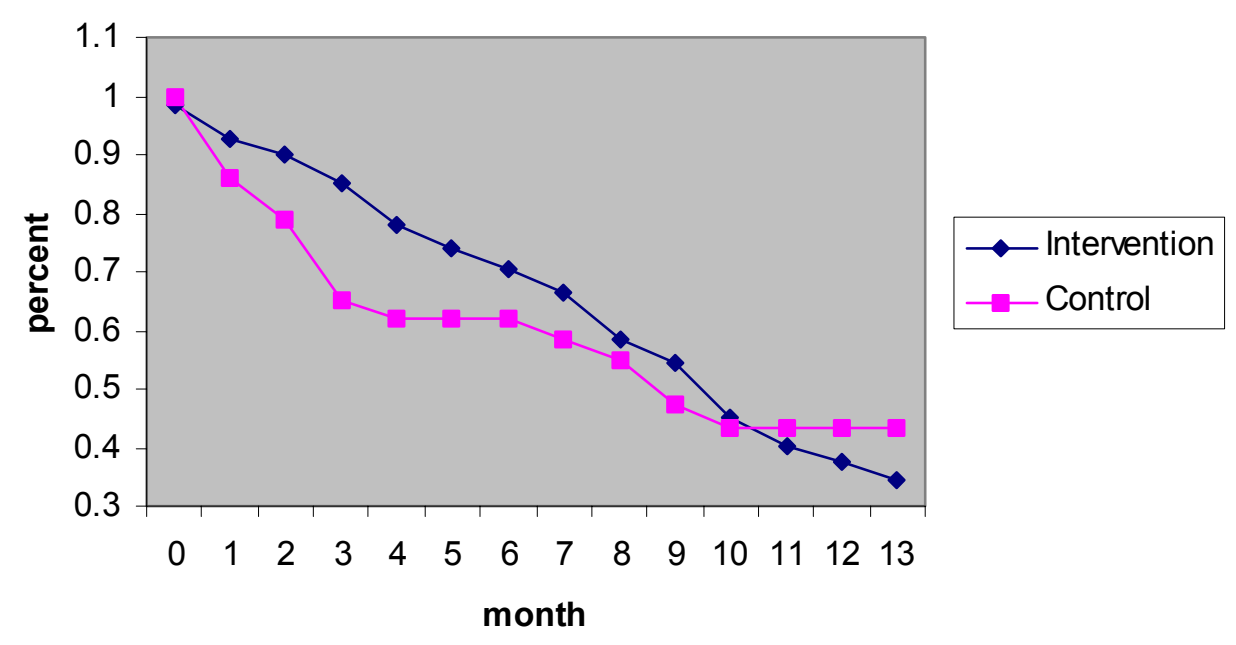




\section{Multiple regression analysis using contraceptive use as dependent variable}

As mentioned earlier in the data entry and analysis section, several models were developed to analyze factors that influence contraceptive use. For each model, logistic regression analysis and stepwise logistic regression analysis were performed. Variables that were found to be significant in each model were included in the final model. This procedure was done for both the seven and 13 month follow-up interviews.

Tables 26 and 27 show the final models developed for the seven and 13 month follow-up interviews. Findings related to the seven month follow-up visit (Table 26) indicate that women who were satisfied with their method, who had more knowledge of correct use of their method, and who were still visiting the same clinic were more likely to continue using a family planning method.

Table 26: Summary of the results of the stepwise logistic regression analysis of the factors related to use of contraception at the seven month follow-up interview

\begin{tabular}{|l|c|c|c|c|}
\hline Variable & B & S.E. & Sig & Odds ratio \\
\hline $\begin{array}{l}\text { Knowledge score of correct use of method } \\
\text { received at index visit }\end{array}$ & .543 & .161 & .001 & 1.72 \\
\hline $\begin{array}{l}\text { Knowledge score of family planning method } \\
\text { received at index visit }\end{array}$ & -.049 & .013 & $<.001$ & .95 \\
\hline Still visit the same clinic & -1.869 & .374 & $<.001$ & .15 \\
\hline $\begin{array}{l}\text { Method satisfaction score (with care } \\
\text { received at index visit) }\end{array}$ & .044 & .008 & $<.001$ & 1.04 \\
\hline Constant & -7.634 & 14.528 & .599 & \\
\hline
\end{tabular}

Some of these findings are also reflected in the 13 month follow-up interview (Table 27). Thus, women who were satisfied with their method, had more knowledge about their method, had no history of child loss, and did not intend to have more children in the future were more likely to continue method use.

Table 27: Summary of the results of the stepwise logistic results analysis of the factors related to use of contraception at the 13 month follow-up interview

\begin{tabular}{|l|c|c|c|c|}
\hline Variable & B & S.E. & Sig & $\begin{array}{c}\text { Odds } \\
\text { ratio }\end{array}$ \\
\hline Method satisfaction score received at index visit & .036 & .008 & $<.001$ & 1.04 \\
\hline Previous child loss & -1.086 & .324 & $<.001$ & 2.96 \\
\hline $\begin{array}{l}\text { Knowledge score of family planning method } \\
\text { received at index visit }\end{array}$ & .283 & .097 & .004 & 1.33 \\
\hline Intention to have more children & -1.434 & .257 & $<.001$ & 0.24 \\
\hline Constant & -2.955 & .832 & $<.001$ & \\
\hline
\end{tabular}

Additional analyses were done to determine what factors might have influenced each of the independent variables that were significantly related to contraceptive use. These analyses were also performed through development of several models.

The dependent factors included in this regard in the case for the seven month follow-up visit for which some independent variables were found to have significant influence on were: 
- Method satisfaction score

- Knowledge of correct use

- Knowledge of the method used

(the above three variables relate to method received at index visit)

- Still visiting the same clinic

Multiple regression analysis showed that the knowledge score on warning signs, knowledge score on correct use, husband's education, and the number of living children are significantly and negatively related to the method satisfaction score. Knowledge score on method used, the satisfaction score with service providers, and obtaining other services at the clinic are positively related to method satisfaction.

With regard to knowledge of correct use, the analysis showed that the intervention was significantly related to knowledge score of correct use. The intervention resulted in better scores. Stepwise analysis indicated that women's education is also positively related to this score.

Considering knowledge of the method used, the results showed that women's age, women's education, and satisfaction with service providers were significantly and positively related to the knowledge score of the method used. The total number of living children was negatively related to this score. Being in the intervention site is also associated with higher scores. The stepwise analysis showed that women's education and satisfaction with service providers and intervention were positively related to this score. With regard to the variable "still visiting the same clinic," the analysis showed that women's age is a significant predicator of continuing visiting the same clinic (i.e., younger women tend to continue visiting the same clinic).

For the case of the 13 month follow-up interview, the following dependent variables were considered (these variables relate to methods received at the index visit):

- Satisfaction with the contraceptive method

- Knowledge score of method received

With regard to satisfaction with the contraceptive method chosen, the analysis showed that knowledge scores of correct use of method and satisfaction with service providers were significantly related to method satisfaction score. The knowledge score was negatively related, while the satisfaction score was positively related. The stepwise analysis added that knowledge scores of warning signs of method used and intervention site were related to the method satisfaction score. The knowledge score on warning signs was positively related to the satisfaction score, while the intervention was associated with a lower satisfaction score, which is an unexpected finding.

With regard to knowledge score of method used, the analysis showed that still visiting the clinic is the only factor significantly related to the knowledge score. Those who continued to visit the same clinic had higher scores. 


\section{QUALITATIVE ANALYSIS OF DISCONTINUATION}

The objective of this section is to report insights underlying the reasons for method discontinuation and the occurrence of pregnancy among study participants, despite reporting at the index visit that they did not plan for a birth in the following 12 months.

Field visits were made to women in the intervention group who became pregnant. In-depth interviews were conducted with those women at their homes by the same interviewers who visited them in the seven and 13 month follow-up interviews. An interview guide was designed for this purpose. A consent form was designed and used to seek approval of the women for conducting the interview and recording it. A total of 22 women were interviewed.

Of the 22 women who became pregnant, three were using a method, and 19 had discontinued their method. Eleven of the 19 who stopped using a method were planning for pregnancy. Of the others, seven women stopped using their method because of side effects, and there was one case of an IUD expulsion. Analysis of qualitative findings showed that women changed their reproductive intentions (also indicated by quantitative data). In some cases, the woman made the decision herself, while in other cases she was pushed to change her decision by her husband and/or mother in law. In some situations, death of a previous child influenced the woman's decision to replace that child. Some unplanned pregnancies occurred due to low quality of care services provided by

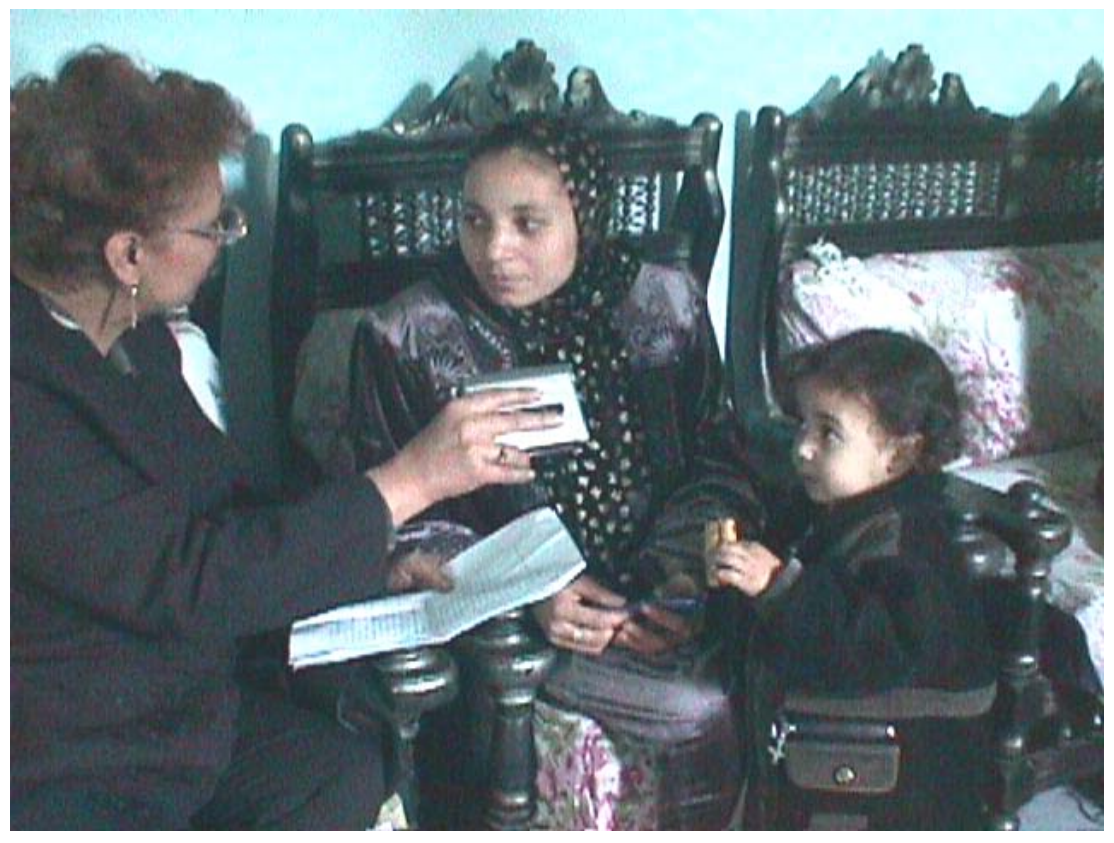
health providers.

Selected cases are presented in Appendix II to provide more details on different factors underlying method discontinuation leading to the occurrence of pregnancies. 


\section{CONCLUSIONS}

This study represents Phase II of a global study that aimed at improving client-provider interaction through the study's intervention package. Client outcome variables were expected to improve as a result of improving client-provider interaction. This study followed a cohort of new family planning acceptors for a period of 13 months after enrollment at the index visit. Client outcome variables were measured at months seven and 13 through home interviews to assess impact of the study interventions.

The study findings indicated that women in the intervention group, though similar to women in the control group, were to some extent less educated and less likely to work outside the home. Socio-economic indicators of women in the intervention group in general were somewhat lower compared with women in the control group.

In addition, women in the intervention group had, on average, higher achieved and desired fertility, experienced a higher level of infant death, and had more living girls. Also, more women in the intervention group still wanted additional children, and among them, the mean number of additional children desired is higher than for women in the control group.

Only about one-half of women in either study group made return visits to index clinics after seven or 13 months of index visit. Even fewer women made follow-up visits as recommended by service providers. Differences between intervention and control groups were small. Some of those women shifted to other sources (hospitals or private physicians), as indicated by findings of the qualitative study. Other studies conducted in Egypt have also indicated that women tend to change service source for various reasons (SPAAC 1994). Thus, women may receive information from different sources, and this information could be contradictory. This would affect women's subsequent behavior with regard to contraceptive use. Therefore, good counseling should not only be provided at method adoption, but also should continue at followup visits. A recent study conducted in Egypt on the impact of menstrual changes on method use reached this same conclusion (Tolley et al. 2003). It is important for women to continue to meet with clinic staff to discuss problems faced with method use (e.g., side effects that could not be tolerated).

Few of the women who did not return to the study clinics were followed-up by clinic staff, with no differences found between study groups. The improvement in providers' technical knowledge, information to be provided to clients, and aspects of client-provider interaction that were documented in Phase I of the study did not result in improvement in clients' knowledge of available family planning methods or method currently used.

The mean percent general knowledge score of family planning methods for the intervention group was 42 percent versus 44 percent for the control group for the seven month follow-up visit. Figures for the 13 month follow-up interviews were 46 percent versus 48 percent, respectively. The same findings were also noted when examining mean general knowledge score for women currently using injectables or pills. However, for women currently using the IUD, the findings indicated improvement in the mean percent general knowledge score about the IUD for 
women in the intervention group (about 26\% and 30\% in the seven and 13 month interviews, compared with $23 \%$ and $26 \%$ in the control group, respectively).

The study findings indicate improvement in the mean general knowledge score of the IUD and pills in the intervention group compared with the control group among women who received those methods in the index visit, and who continued using them through the 13 month interview. For instance, the mean percent score for the IUD for the intervention group was 51 percent versus 46 percent for the control group at the seven month interview, and 60 percent versus 53 percent at the 13 month interview, $\mathrm{p}<0.01$.

LAM is an important form of natural family planning that is widely practiced among Egyptian woman, especially in rural areas. However, the findings indicate that most women do not know how to use it effectively. The majority of women in both study groups know only one criterion for LAM to be an effective method of family planning (absence of menses). More women in the control group than in the intervention group knew about it at the seven month follow-up visit $(65.7 \%$ versus $50.5 \%)$, and at the 13 month interview $(81.4 \%$ versus $61.4 \%, \mathrm{p}<0.01)$. Very few women reported knowledge of the other two criteria (breastfeeding up to 6 months after delivery, and exclusive breastfeeding). Overall, the mean percent knowledge score on the three criteria was higher among women in the control group compared to women in the intervention group in both follow-up visits.

Knowledge of the warning signs of family planning methods was higher among women in the intervention group compared with women in the control group, with few exceptions. The mean percent knowledge score of warning signs for women currently using the pill in the intervention group was 44 (out of 100) compared to 35 for the control group for the seven month follow-up visit. The mean scores were also higher for the IUD and injectables in the intervention group, but the differences were not significant.

The mean percent score of knowledge of correct IUD use was higher among women using the method in the intervention group compared to the control at both the seven and 13 month followup interviews. The mean percent score of knowledge of correct IUD use was 41.4 in the intervention group versus 36.9 in the control group at the seven month interview. Comparable figures for the 13 month interview are 45.1 percent versus 39.8 percent. This an important finding since the majority of women in Egypt use the IUD; according to the Egypt 2000 DHS 63 percent of contracepting women use the IUD (El Zanaty and Way 2001). The study findings also indicate that about 60 percent of women in both study groups were using the IUD.

Once they received a method at the index visit, about one-quarter of women in both study groups switched to another method during the period between the index visit and the 13 month followup interview. Switching to the second method occurred after a fairly short period of method discontinuation (mean period $=1.03$ moths for the intervention and 0.90 for the control, $\mathrm{p}<0.01$ ). This may be considered prompt switching.

The study findings did not indicate large differences between the two study groups with regard to satisfaction with the method received at the index visit. Although the majority of women 
reported satisfaction with the method received at the index visit, the differences were not significant between groups.

Unexpectedly, the study findings reflected rather low levels of knowledge about method side effects among the two study groups. Knowledge of pill side effects was less than 30 percent for both study groups, while knowledge of IUD side effects was about 37 percent for both study groups. In general, women in the intervention group were more likely to experience side effects of IUDs, and more likely to be able to tolerate side effects of IUDs and injectables compared with women in the control group. It is possible that better knowledge about side effects leads to more ability to tolerate them. This relationship needs more investigation to establish, however. Suffering from method side effects has been indicated as the major reason for discontinued method use in fertility surveys in Egypt. The Egypt 2000 DHS found that about 40 percent of discontinuers reported method side effects as the reason for discontinuation (El Zanaty and Way 2001). This is a key concern for policymakers in Egypt.

Client satisfaction with services provided at the study clinics was found to be the outcome indicator that showed the most difference between study groups. About 76 percent of women in the intervention group were satisfied with the physical aspects of clinic preparedness at the seven month follow-up visit as compared with 31 percent of women in the control group. Comparable figures for the 13 month follow-up interview were 88 percent versus 32 percent $(p<0.01)$. Likewise, satisfaction with clinic services received at the index visit (providers' counseling skills and technical competence) was significantly higher among women in the intervention group as compared with women in the control group at both follow-up visits $(72 \%$ versus $55 \%$, and $81 \%$ versus $61 \%$ at the seven and 13 months follow-up visits, respectively, $\mathrm{p}<0.01)$.

The data also indicated that between one-third and two-fifths of women in the two study groups who discontinued using a method ( $9 \%$ to $17 \%$ of all women) changed their reproductive intentions since the index visits, at which they reported wanting no more children. Decisions on changing reproductive intentions were not generally made by women. In many cases, the decisions were made by husbands and/or mothers-in-law, reflected in the qualitative study findings.

Few women were not able to achieve their reproductive intentions. They were exposed to unplanned pregnancy due to various reasons (e.g., incorrect method use, method side effects, health concerns) reflecting poor quality of care and counseling. About two-fifths of women of both study groups who discontinued method use fall in this category. However, it may not be realistic to conclude that the study intervention was not able to help these women avoid unplanned pregnancy. Again, the qualitative findings indicated that some women change service source (e.g., go to the private sector), believe myths, rumors or misconceptions regarding use of some contraceptive methods, and delay seeking medical advice when faced with warning signs.

The findings indicated above, however, do not imply that there were no gaps in service provision. The qualitative study revealed that in some situations physicians were not available to react to women's queries; they were too busy with other activities (such as vaccinations), or they provided inaccurate advice. These situations need further follow-up and investigation. 
Finally, the study findings did not reveal significant differences in method continuation rates between the two study groups. Both study groups experienced similar continuation rates for the IUD (life table cumulative rates were 80 percent for both groups after 12 months of use). Multiple regression analysis showed that women who were satisfied with the method and who had greater knowledge about its correct use were more likely to continue method use. Also, women who continued visiting the index clinic continued method use longer than women who did not return to the index clinic. These findings are not surprising and confirm the importance of providing good counseling on contraceptive methods, and the importance of follow-up visits.

\section{RECOMMENDATIONS}

- IEC

$\checkmark$ Continue to develop and test innovative, attractive and well-designed IEC messages that influence woman's fertility preferences. These messages should cater to different types of clients and should be grounded in evidence-based messages derived from recent studies with sound methodologies.

$\checkmark$ Further develop IEC components that promote women's knowledge about criteria for effective LAM as a family planning method. Many projects have focused on educating women about LAM as a natural family planning method, yet women's knowledge about LAM continues to be deficient. Media may be capitalized on as a good means for disseminating this information.

\section{- Continuous training of health providers}

$\checkmark$ Provide continuous training to clinic health providers to demonstrate sensitivity and understanding of women's needs in their localities. They should be able and willing to educate their clients in a culturally sensitive manner. They should also ensure retention of knowledge. The clinic staff is an important source of health education and information, and should be able to provide proper counseling and make clients feel that they are approachable.

$\checkmark$ Continue to emphasize the importance of encouraging women to make regular clinic follow-up visits as well as to seek medical advice when faced with problems with method use. Helping women manage method side effects and advising them to promptly switch methods should limit method discontinuation and/or unplanned pregnancies

\section{- Policy}

$\checkmark$ Consider reasonable and realistic mechanisms to train private physicians and service providers of other programs. At a minimum, training materials should be available to them. In shifting from one health facility to another, women should receive the same basic information and counseling. While the base information could be brief and deal with few information areas as a first step, it may expand later as needed if proven to be useful. 


\section{APPENDIX I}

\section{Description of Indices}

1. Client socio-economic status score: This includes 14 variables with the value one for possession or zero for no possession: (1) Material of floor is cement tiles or any better material (yes=1/no=0); (2) Mean number of persons in the dwelling (if $\leq=4=1 />4=0$ ); (3) Household connected to piped water (yes $=1 / \mathrm{no}=0)$; (4) Flush toilet is available (yes $=1 / \mathrm{no}=0)$; (5) Toilet is shared with others (yes $=0 / \mathrm{no}=1) ;(6)$; Electricity is available (yes=1/no=0); (7) Radio with cassette player $($ yes $=1 /$ no=0); (8) T.V. (yes=1/no=0); (9) Telephone (yes $=1 / \mathrm{no}=0) ;(10)$ Electric fan $(\mathrm{yes}=1 / \mathrm{no}=0) ;(11)$ Heater $(\mathrm{yes}=1 / \mathrm{no}=0) ;(12)$ Refrigerator (yes=1/no=0); (13) Sewing machine (yes=1/no=0); (14) Manual washing machine $(\mathrm{yes}=1 / \mathrm{no}=0)$. The composite socio-economic status score has a value between zero and 14.

2. Knowledge score of criteria for LAM to be effective as a family planning method: The score includes three questions: (1) breastfeeding up to six months after delivery; (2) exclusive breastfeeding; (3) no menstruation. The question has a value of zero if the client did not mention the correct answer or does not know, and one if she mentioned the correct answer. The score has a value between zero and three. It was then computed relative to 100 .

3. General knowledge score of method currently used (IUD, injectables, pills): All the questions have a scale of zero (if the client did not mention the correct answer or does not know) and one (if the client mentioned the correct answer). All questions starting from question 413 (1-25) and question 414 (1-9) on the questionnaire were included. A total score was computed for each client with a possible score range of zero to 53 .

4. Knowledge of possible danger signs: All the questions have a value of zero (if the client did not mention the correct answer or does not know) and one (if the client mentioned the correct answer). For the pill questions included: (1) What should you do if you miss two periods? (2) What should you do if you get very bad headaches? (3) What should you do if you have severe chest pain? (4) What should you do if you have problems breathing? (5) Which alarm signs regarding your legs should you have in mind if you are taking the pills? (6) What should you do if your skin or eyes turn yellow while you are taking the pills? and (7) What could be a danger sign for the pills related to your vision? A total score was computed for each client with a possible score range from zero to seven. The score was then computed relative to 100. For the IUD the two questions were: (1) What should you do if your menstrual cycle is severe or you have fever? and (2) What should you do if you miss two periods? A total score was computed for each client with a possible score range of zero to two. The score was then computed relative to 100. For the injectable, the two questions were: (1) What should you do if you experience chest pain while using the injectable? and (2) What should you do if you have breathing problems while using the injectable? A total score was computed for each client with a possible score range between zero and two. The score was then computed relative to 100 . 
5. The mean knowledge score of correct use (pill, IUD, injectable): All the questions have a value of zero (if the client did not mention the correct answer or does not know and one (if the client mentioned the correct answer). For the pill, questions included: (1) How frequently the woman should take the pills? (2) When do you have to start with the next? (3) What should you do if you forget to take a pill for one day? and (4) What should you do if you forget to take the pill for more than one day? A total score was computed for each client with a possible score range between zero and four. The score was then computed relative to 100. For the IUD, questions included: (1) What should you do to make sure that your IUD is in the right place? (2) What should you do if you check your IUD and do not find the string? and (3) How frequently should you do it? A total score was computed for each client with a possible score range between zero and three. The score was then computed relative to 100 . For the injectable the two questions were: (1) How often do you have to get the injection? and (2) Can you take your injectable out of date, and when? A total score was computed for each client with a possible score range between zero and two. The score was then computed relative to 100 .

6. The mean satisfaction score with method received at index visit: All the questions have a value of zero (if the client is not satisfied with the method), one (if client is moderately satisfied with the method), or two (if client is strongly satisfied with the method). The questions were: (1) Are you satisfied with the obtained methods? (Strongly satisfied $=2$ / moderately satisfied or slightly satisfied $=1$ / not satisfied $=0$ ); (2) Is the way of using the obtained method suitable to you? (Totally suitable $=2 /$ moderately suitable or slightly suitable $=1 /$ not suitable at all $=0$ ); (3) How much do you feel protected using this method? (totally safe $=2 /$ almost safe or some doubts $=1 /$ not safe $=0$ ); (4) Do you have any follow-up problems with the obtained method? (none $=2 /$ minor or some problems $=1 /$ lot of problems $=0)$; (5) To what extent is your husband satisfied with the obtained method? (Strongly satisfied $=2 /$ moderately or slightly satisfied $=1 /$ not satisfied $=0)$; (6) Do you have any problems during intercourse with use of the obtained method? (none $=2 /$ minor problems $=1 /$ lot of problems $=0$ ); and (7) What is your opinion about the cost of using the method? $($ cheap $=2 /$ reasonable $=1 /$ expensive $=0)$. A total score was computed for each client with a possible score range between zero and seven. The score was then computed relative to 100 .

7. Scores on knowledge of method side effects, experience of them and ability to tolerate them: For the method received at index visit, women were asked about method side effects, whether she experienced any of them and, if yes, if she was able or not able to tolerate method side effects. For each question, answers took value of $1=$ (if she knows each side effect, has experienced it, can tolerate, cannot tolerate) or $0=$ otherwise. For the pill the score value ranged between 0-7. For both the IUD and injectables the score value ranged between 0-5. All scores were then computed relative to 100 .

8. Clinic's physical preparedness for providing family planning services score: Aspects of clinic preparedness included: 1) condition of waiting area (was there a waiting area) $(\mathrm{yes}=1 / \mathrm{no}=0) ;(2)$ cleanliness of waiting area (very clean $=1 /$ moderately clean or $n o=0)$; (3) was there a privacy during consultation ( $\mathrm{yes}=1 / \mathrm{no}=0$ ); (4) was there privacy during examination (yes $=1 / \mathrm{no}=0)$; (5) condition of toilet (availability of toilet, cleanliness, and 
suitable for use) $(\mathrm{yes}=1 / \mathrm{no}=0)$. A total score of preparedness indicator has a value ranging between zero and five. The score value was then computed relative to 100 .

9. Client's satisfaction score with service providers: This score was measured on a scale of zero to13. The provided questions were: (1) Did health providers give you a chance to tell them about your problems/needs? (excellent chance=1/good or no chance $=0$ ); (2) Did the providers explain all the contraceptive methods which are available at the clinic? (talked about all methods=1/talked about the method I got only or no=0); (3) Did the doctor perform a breast exam? (yes $=1 / \mathrm{no}=0$ ); (4) Did the doctor perform a pelvic exam? (yes $=1 / \mathrm{no}=0$ ); (5) Did health providers perform lab tests before giving the method? (detailed tests $=1 /$ simple test or no=0); (6) Did the doctor explain to you the unsuitable methods for you? (told me about the unsuitable methods=1/ quick idea or no=0); (7) Who chose the method you received? (Doctor and $\mathrm{I}=1 /$ my choice or doctor alone $=0$ ) ( 8 ) Did the doctor talk about the advantages and disadvantages of the obtained method? (advantages \& disadvantages $=1 /$ either advantages or disadvantages or no=0); (9) Did the doctor explain the side effects of the obtained method? (talked in detail=1/ general idea or no=0); (10) Did the doctor give you a good and clear idea about how to use the obtained method ? (talked in detail=1/ general idea or no=0); (11) Did doctor tell you to come back to the clinic for follow-up? (explained follow-up schedule follow-up=1/asked me to come back or no=0); (12) Did the doctor discuss with you how to protect yourself from STIs? (yes $=1 / \mathrm{no}=0$ ); and (13) Did you feel that the providers treated you with respect and were concerned about your health, and would you advise your neighbors to visit the clinic for family planning services? (yes $=1 / \mathrm{no}=0$ ). The satisfaction with services received score was computed with a possible score range of zero to 13 . The score was then computed relative to 100 . 


\section{Appendix II}

\section{Case Studies from the Qualitative Research Findings}

\section{Changing Reproductive Intentions}

\section{Case 1: Changed plans}

She is 22 years old and her husband is 31 . Both had secondary education. She had now (at the time of the interview) a son and a daughter. She used the IUD after the birth of her first child (son) but did not feel comfortable with it. She switched to the pills and intended to use them for 2-3 years. As she said, she changed her mind and decided to stop method use and became pregnant. Her son is getting older, and she wanted another child sooner.

Her husband agreed with her. She conceived her daughter, and she is now using an IUD. She and her husband are planning to have two or three children.

\section{Case 2: Husband}

She is 22 years old and her husband is 32 . She had a daughter and she is currently pregnant (at the time of the visit) with a male fetus. Her husband does not know the sex of the child. She was not intending to have a second child because she is suffering from back problems. Her motherin-law, who is also her aunt, is concerned about her health. Her mother-in-law has no influence on decisions regarding family size.

She was using an IUD. Because of her health problems (back) she intended to use contraceptives for three years to continue breastfeeding her infant and also to have rest for her health. This decision was shared with her husband. But her husband changed his mind and wanted another child

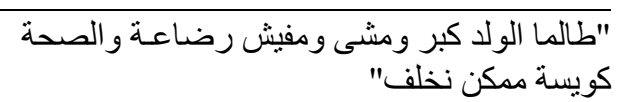

"As long as my son is growing and started walking and I'm not breastfeeding him and my health is good, I can get pregnant again." sooner. She was afraid of having health problems, but he assured her that nothing would happen as she would follow-up her pregnancy with a physician. For religious reasons, she did not like to disobey him. She did not try to discuss with him why he changed his mind. Accordingly, she went to the local health facility (intervention clinic) where she initially had the IUD inserted and had it removed. The physician there removed it without discussing the reasons for removal, but the nurse tried to convince her to postpone removal to allow for breastfeeding and for her own health.

\section{Case 3: Husband and mother-in-law}

She is 30 years old and her husband is 34 . She did not complete preparatory education and her husband had higher education. She had three sons, and she lost two girls. She considered using contraception after approval of her husband. He did not want her to use an IUD or

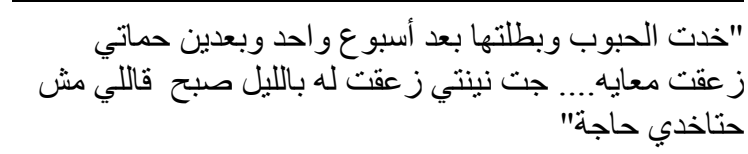

"I took pills for one week then my mother-in-law scolded me ... my mother in law reprimanded him (my husband) in the evening ... the next morning he told me that I should not take the pills." 
injectables. She used the pills for one week then she stopped because her mother-in-law objected, and her husband changed his mind.

Her husband is the only son of his mother, and his mother wants to have many grandchildren. She got pregnant and had a daughter.

\section{Case 4: Infant death}

She is 24 years old and her husband is 34 . She attained a university education, and he attained a high technical education. She was using the IUD after she delivered her first girl child, and was intending to use it for 18 months. This was a joint decision with her husband. They were planning to have two children. Her child died at six months, so she had the IUD removed in order get pregnant.

\begin{tabular}{l}
\hline "أنا بنتي إتوفت ورحت شلت اللولب" \\
"My daughter died, so I removed the \\
IUD."
\end{tabular}

She delivered a baby boy, who was less than 40 days old at the time of the interview.

\section{Unplanned Pregnancies}

\section{Case 5: Side effects}

She is 32 years old and her husband is 30 . She had 5 deliveries but 2 children died, and she had (at the time of the visit) one boy ( 3 months old) and two girls. She started to use contraception because she and her husband were not willing to have more children, as her husband has no permanent job. She used injectables for two years and then she switched to the IUD because of amenorrhea. She heard that the injectables causes infertility, and enlargement of uterus (tumors)

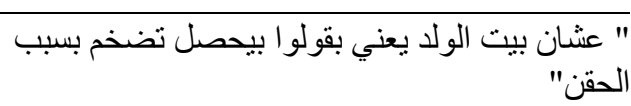

"They say enlargement of the womb happens because of injectables."

She mentioned that the physician (female) of the local health facility (intervention clinic) advised her to stop injectables for a couple of months because she had hypertension. She went to a nearby health facility outside her village to insert an IUD because she heard that the physician at the local health facility is not good in inserting the IUD, and the nearby facility is larger with better preparation for emergencies.

While she was using the IUD, she lost a son in an accident. During her grief she had bleeding. She went to the facility where she had the IUD inserted, and her physician removed the IUD and gave her injectables to stop the bleeding. He advised her not to use any contraceptive method after then because she was weak. He assured her that she would not get pregnant and he did not ask her to come back after cessation of the bleeding to use a method. Then she became pregnant.

She said that when she got pregnant, her husband refused an abortion. She now (at the time of the visit) depends on lactational amenorrhea as a family planning method.

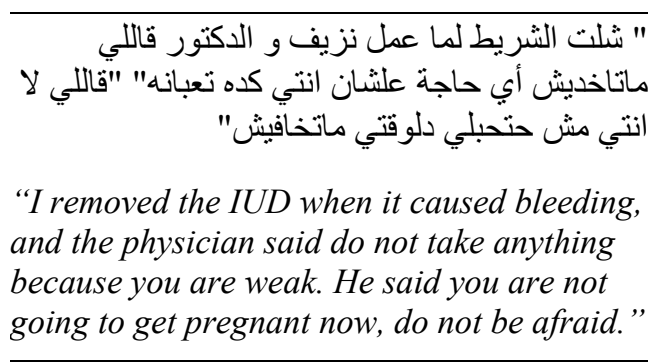




\section{Case 6: Side effects}

She is 23 years old and her husband is 28 . She had one daughter and she is pregnant with the second child (5 months). She was planning to postpone pregnancy for about 4 years. She had an IUD inserted but suffered from bleeding. She had it removed after about 4 months and had another IUD inserted at an intervention clinic. She had abdominal pains. She visited the clinic twice for advice but she did not find the physician at one time and at the second time they were busy with vaccination. After that she visited a private physician (with rather expensive fees

$$
\begin{aligned}
& \text { " قولتله أنا مش عاوزه دلوقتي لكن قاللي خليها المرة دي }
\end{aligned}
$$

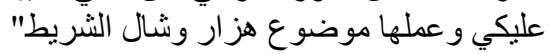

"I told him that I do not want children now, but he said take it on your own this time and he made it a joke and removed the IUD."

for her) who told her that she had inflammations and asked her about the age of her daughter, and he advised her to get pregnant. She told him that she did not want another child now.

He removed the IUD that she had for seven months. Her husband was upset and wanted her to insert another IUD for one year, but she was tired. She added that she did not want to use the injectable because it causes bleeding if used after the IUD. She said also that all who use the pills are complaining.

She intended to use the implants after delivery, although they cause impairment in the movement of the arm but this for her is better than bleeding.

\section{Pregnancy}

\section{Case 7: While using IUD}

She is 22 years old and her husband is 25 . She now has two children. Between these two children, she visited one of the intervention clinics to obtain a contraception method. She was informed about the different methods and she chose the IUD. The IUD was inserted, and she visited the clinic for a follow-up and she was told that the IUD was fine. She was taught how to check the threads and told to check them regularly. She tried to check the threads but she did not find them. A woman told her that not every woman could detect them.

She went to the clinic; the physician did not find the threads. She asked her to do a pregnancy test, which was positive. She went to a private physician who told her that it was not correctly inserted. He confirmed that she was pregnant. Six weeks after the delivery of her second child, her private physician inserted a new IUD. She checks the threads regularly and visits the physician monthly for follow-up.

\section{Case 8: Incorrect method use}

She is 35 years old and her husband is 32 . They have five children ( 3 girls and 2 boys). Her youngest child is 27 days old. They had previously lost another child. She was using pills regularly for three months. Then she had an accident. She fell down the stairs and she stayed in 
bed for about 20 days. During the period of illness she was confused, and did not know if she took the pill. She did not use the pill regularly as she was using other medications.

She used the pills again after her illness for about two months, but she did not feel well. She went to the physician, who performed tests. He told her that she is pregnant.

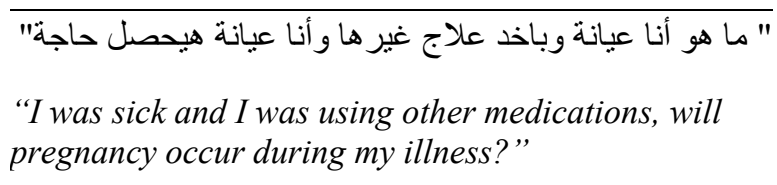

She said that she was informed in the clinic during earlier visits that if she stopped the pills she would become pregnant. She intends to use the IUD within two weeks (40 days from delivery). Her husband agreed on using the IUD. Her mother-in-law does not interfere in these issues. 


\section{REFERENCES}

El-Zanaty, Fatma and Ann Way. 2001. Egypt Demographic and Health Survey 2000.

Calverton, Maryland: Ministry of Health and Population (Egypt), National Population Council and ORC Macro.

El Zanaty \& Associates. 1998. "Quality of Care and Family Planning Utilization in Ministry of Health and Population Clinics.” Cairo: National Population Council.

León, Federico R., Santiago Roca, Alex Ríos, Adriana Zumarán, Ana Rosa Feijoo. 2003. "OneYear Client Impacts of Quality of Care Improvements Achieved in Peru," FRONTIERS Final Report. Washington: Population Council.

Okullo, Joel, Quinto Okello, Harriet Birungi, Ian Askew, Barbara Janowitz, Carmen Cuthbertson, and Florence Ebanyat. 2003. "Improving quality of care for family planning services in Uganda," FRONTIERS Final Report. Washington, DC: Population Council.

Social Planning, Analysis and Administration Consultants (SPAAC). 2002. "Impact of Improved Client-Provider Interaction on Women's Achievement of Fertility Goals," FRONTIERS Report. Washington, DC: Population Council.

Social Planning, Analysis and Administration Consultants (SPAAC). 1994. "Profile of Clients of Different Providers of Family Planning Services in Egypt," Asia and Near East Operations Research and Technical Assistance Project Final Report. Cairo: Population Council.

Tolley, Elizabeth, Stirling, Sarah Loza, and Laila Kafafi. 2003. “The Impact of Menstrual Changes on Method Use: A Comparative Study Among Egyptian Women Using the IUD, DMPA and Norplant," Final Report. Research Triangle Park, North Carolina: Family Health International. 